M. Mancini and M. Alberti and M. Dammann and U. Santo and G. Eckel and T. Kolb and R. Weber, Entrained flow gasification. Part 2: Mathematical modeling of the gasifier using RANS method, Fuel, volume 225 (2018) page 596 - 611

The original publication is available at www.elsevier.com

http://doi.org/10.1016/j.fuel.2018.03.100

(C) 2018. This manuscript version is made available under the CC-BY-NC-ND 4.0 license http://creativecommons.org/licenses/by-nc-nd/4.0/ 


\title{
ENTRAINED FLOW GASIFICATION \\ PART 2: Mathematical modeling of the gasifier using RANS method
}

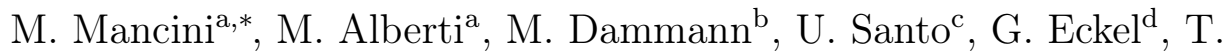 \\ Kolb $^{\mathrm{b}, \mathrm{c}}, \mathrm{R}$. Weber ${ }^{\mathrm{a}}$ \\ ${ }^{a}$ Clausthal University of Technology, Institute for Energy Process Engineering and Fuel \\ Technology (IEVB), Agricolastrasse 4, 38678 Clausthal-Zellerfeld, Germany \\ ${ }^{b}$ Karlsruhe Institute of Technology (KIT), Engler-Bunte-Institute, Division of Fuel \\ Technology (EBI ceb), Engler-Bunte-Ring 3, 76131 Karlsruhe, Germany \\ ${ }^{c}$ Karlsruhe Institute of Technology (KIT), Institute for Technical Chemistry (ITC), \\ Herrmann-von-Helmholtz-Platz 1, 76344 Eggenstein-Leopoldshafen, Germany \\ ${ }^{d}$ German Aerospace Center (DLR), Institute of Combustion Technology, Pfaffenwaldring \\ 38-40, 70569 Stuttgart, Germany
}

\begin{abstract}
CFD (RANS based) simulations of REGA-1 experimental campaign concerning gasification of glycol in an oxygen-nitrogen mixture have been carried out. The reacting flow-field has been computed using a number of turbulence models while turbulence-chemistry interactions have been modeled using either the Eddy Dissipation Concept (EDC) or the presumed PDF approach. Two global-chemistry schemes have been used: the (HVI1) scheme for glycol gasification and the extended Jones-Lindstedt scheme. Radiation has been computed using the Discrete Ordinate Method with a comprehensive analysis concerning absorption/emission of infrared radiation by gaseous molecules as well as absorption and scattering on droplets. The CFD-predictions of the near-atomizer region have been sensitive to and strongly dependent on the sub-models used; the spray sub-model and the chemical schemes are the most
\end{abstract}

\footnotetext{
${ }^{*}$ Corresponding author

Email address: mancini@ievb.tu-clausthal.de (M. Mancini)
} 
important. Good quality predictions of temperature and chemical species ( $\mathrm{CO}, \mathrm{H}_{2}, \mathrm{CO}_{2}, \mathrm{H}_{2} \mathrm{O}, \mathrm{CH}_{4}$ ) concentrations at $300 \mathrm{~mm}$ and $680 \mathrm{~mm}$ distances from the atomizer have been obtained. The HVI1 global chemistry scheme has predicted very well not only the $\mathrm{CO} / \mathrm{CO}_{2}$ ratios but also the trace concentrations of methane. The paper shows how to simplify the radiative heat transfer simulations without a significant loss in accuracy.

Keywords: CFD, RANS, Entrained Flow, Gasification, Ethylene glycol

\section{List of Symbols}

\section{Greek Letters}

$\beta \quad$ Second viscosity

$\mathrm{kg} \mathrm{m} / \mathrm{s}$

$\delta_{i j} \quad$ Kronecker delta

$\epsilon_{p} \quad$ Droplet emissivity

$\eta \quad$ Wavenumber

$m$

$\gamma^{*} \quad$ Fine structure mass to the total mass ratio

$\mu \quad$ Dynamic viscosity

$\mathrm{kg} \mathrm{m} / \mathrm{s}$

$\nu_{p} \quad$ Stoichiometric coefficients for products

$\nu_{r} \quad$ Stoichiometric coefficients for reactants

$\Omega \quad$ Solid angle

str

$\Phi \quad$ Dissipation by viscous stress

$k J /\left(m^{3} s\right)$

$\Phi_{\eta} \quad$ Scattering phase function

$\rho \quad$ Density

$k g / m^{3}$ 
$\rho_{p} \quad$ Droplet density

$k g / m^{3}$

$\sigma \quad$ Stephan-Boltzmann constant

$W /\left(m^{2} K^{4}\right)$

$\sigma_{f} \quad$ Variance of the mixture fraction

$\sigma_{\eta, s} \quad$ Gas scattering coefficient

$1 / m$

$\tau^{*} \quad$ Eddy characteristic time scale

$S$

$\tau_{e} \quad$ Eddy characteristic lifetime

$S$

$\theta_{R} \quad$ Radiation temperature

$K$

$\varepsilon \quad$ Turbulent energy dissipation

$m^{2} / s^{3}$

$\xi \quad$ Limiting factor for reaction rate in the fine structures

\section{Non-dimensional Numbers}

$B \quad$ Spalding mass transfer number

$\mathrm{Nu} \quad$ Nusselt number

Pr Prandtl number

Re Reynolds number

$R e_{p} \quad$ Droplet Reynolds number

Sc Schmidt number

Sh Scherwood number

\section{Roman letters}

$\dot{m}_{e} \quad$ Evaporation rate per unit of surface

$k g /\left(m^{2} s\right)$ 
$\dot{m}_{M E G}$ MEG mass flow rate

$$
\begin{array}{r}
k g / h \\
k g / h \\
k g / h \\
k J /\left(m^{3} s\right) \\
k W /\left(m^{2} s\right) \\
k g /\left(m^{3} s\right)
\end{array}
$$

$\dot{m}_{N_{2}} \quad$ Nitrogen mass flow rate

$\dot{m}_{\mathrm{O}_{2}}$ Oxygen mass flow rate

$\dot{Q} \quad$ Heat source/sink

$\dot{q}_{w} \quad$ Wall heat flux

$\dot{s}_{m} \quad$ Mass sources

$\mathbf{a}_{d} \quad$ Acceleration due to drag force

$\mathrm{m}^{2} / \mathrm{s}$

D Stress tensor

$k g /\left(m^{2} s\right)$

g Gravity acceleration

$m^{2} / s$

$\mathbf{J}_{i} \quad$ Mass transfer flux

$k g /\left(m^{2} s\right)$

$\mathbf{J}_{t, i} \quad$ Turbulent mass transfer flux

$\mathrm{kg} /\left(\mathrm{m}^{2} \mathrm{~s}\right)$

$\mathbf{q}_{\mathbf{c}} \quad$ Heat flux vector

$k W / m^{2}$

$\mathbf{q}_{\mathbf{m}} \quad$ Multicomponent enthalpy flux vector

$k W / m^{2}$

$\mathbf{q}_{\mathbf{t}} \quad$ Turbulent enthalpy flux vector

$k W / m^{2}$

T Turbulent Reynolds Stress tensor

$k g /\left(m^{2} s\right)$

$\mathbf{u}_{\text {rel }}$ Relative velocity

$\mathrm{m} / \mathrm{s}$

U Fevre averaged gas velocity

$\mathrm{m} / \mathrm{s}$

$\mathbf{u}_{p} \quad$ Droplet velocity

$\mathrm{m} / \mathrm{s}$

$\mathbf{x}_{p} \quad$ Droplet position

$m$ 
A Arrhenius rate constant

$A_{p} \quad$ Droplet external surface

$m^{2}$

$a_{\eta} \quad$ Spectral gas absorption coefficient

$1 / m$

$a_{f} \quad$ Forwards reaction order

$a_{k} \quad$ Absorption coefficient for band $k$

$1 / m$

$a_{r} \quad$ Backwards reaction order

b Temperature exponent

$c_{p} \quad$ Droplet specific heat capacity

$k J(k g K)$

$d_{p} \quad$ Droplet diameter

$m$

$D_{t} \quad$ Turbulent molecular diffusivity

$k g /(m s)$

$D_{\text {eff }} \quad$ Effective molecular diffusivity

$k g /(m s)$

$D_{i, m} \quad$ Molecular diffusivity

$\mathrm{m}^{2} / \mathrm{s}$

E Activation energy

$J / k m o l$

e $\quad$ Specific total energy

$k J / k g$

f Mixture fraction

$h \quad$ Specific enthalpy

$k J / k g$

$h_{g} \quad$ Convective coefficient

$k W /\left(m^{2} K\right)$

$I_{k} \quad$ Radiation intensity in band $k$

$W / s t r$

$I_{\eta, b} \quad$ Black body spectral intensity

$W /(\operatorname{str} m)$ 
$I_{\eta} \quad$ Spectral intensity

$I_{k, b} \quad$ Black body intensity for band $k$

$k \quad$ Turbulent kinetic energy

$k_{e} \quad$ Mass transfer coefficient

$k_{g} \quad$ Gas thermal conductivity

$k_{t} \quad$ Turbulent thermal conductivity

$k_{w} \quad$ Wall thermal conductivity

$k_{b} \quad$ Backwards reaction rates constant

$k_{e f f} \quad$ Effective thermal conductivity

$k_{f} \quad$ Forwards reaction rates constant

$m_{p} \quad$ Droplet mass

$p \quad$ Pressure

$R \quad$ Universal gas constant

$r_{e v} \quad$ Specific evaporation enthalpy

T Gas temperature

$T_{\infty} \quad$ Local temperature of the gas-phase

$T_{h e} \quad$ Temperature of the heating elements

$T_{p} \quad$ Droplet temperature

$T_{w} \quad$ Wall Temperature
$W /(\operatorname{str} m)$

$W / s t r$

$m^{2} / s^{2}$

$k g /\left(m^{2} s\right)$

$k W /(m K)$

$k W /(m K)$

$k W /(m K)$

$k W /(m K)$

$k g$

$P a$

$J /(k m o l K)$

$k J / k g$

$K$

$K$

$K$

$K$

$K$ 
$u_{i}^{\prime} \quad$ Turbulent velocity fluctuation $\mathrm{m} / \mathrm{s}$

$w_{k} \quad$ Temperature weighting function for band $k$

$Y \quad$ Mass fraction

\section{Introduction and Objectives}

2

The modeling and simulation of entrained flow gasification has been a challenge for more than four decades. Due to various designs of entrained flow gasifiers (two-stage up-flow, one-stage down-flow) and different operating conditions (in particular pressure), a great number of studies have been performed. The studies, up to the 1990s, used mainly one-dimensional models of coal gasification (see e.g. Wen [1], Govind [2]) but, despite large dimensions of entrained flow gasifiers, and limited computer resources of the time, few CFD studies [3-11] have also been performed. Since then the number of works based on CFD calculations has significantly increased. Although most of these studies considered different kinds of gasifiers and used different CFD codes (in-house, Fluent, ANSYS Fluent, CFX, OpenFOAM), there are quite a few similarities, namely the use of a RANS turbulence model or the employment of a simplified reaction mechanism for the gas-phase kinetics based on the publications of Westbrook and Dryer [12], and Jones and Lindstedt [13]. Reactions of the char with $\mathrm{CO}_{2}, \mathrm{H}_{2}, \mathrm{H}_{2} \mathrm{O}$ and $\mathrm{O}_{2}$ have often been implemented employing kinetics either taken from literature or measured. Radiation has been described using one of the common models (Discrete Ordinate Method, P1 model, Discrete Transfer Radiation Model). Many research groups have carried out simulations to improve sub-models (e.g. devolatilization, chemical reactions, and slagging), to generate information important for the gasifier design, or to demonstrate that a CFD model 
can be applied to compute both the composition and the temperature at the gasifier exit. Sensitivity analysis of operating parameters $\left(\mathrm{O}_{2} / \mathrm{C}\right.$-coal ratio, $\mathrm{H}_{2} \mathrm{O} / \mathrm{C}$-coal ratio, coal type, coal properties) and unknown model parameters (e.g. homogeneous and heterogeneous reaction rates) have often been carried out [8-11].

Brown et al. [3, 4] investigated coal gasification and measured concentrations of $\mathrm{CO}, \mathrm{CO}_{2}, \mathrm{H}_{2}$, and $\mathrm{H}_{2} \mathrm{O}$ at different axial and radial positions in the Brigham Young University (BYU) atmospheric entrained flow gasifier. They employed the PCGC-2 CFD code to compare the simulation results with the measured data and to analyze the effects of gas-phase chemistry, heterogeneous reaction rates, and operating conditions.

Fletcher et al. [6, 7] carried out simulations of biomass gasification in an up-flow gasifier and investigated sensitivity of the predictions to the turbulence model used. They concluded that inside the diffuser section, the flow could be better predicted by applying the Differential Reynolds Stress Model than the standard k- $\epsilon$ model. The simulations provided results consistent with measurements.

Chen et al. [8-11] and Liu et al. [14-17] performed extensive sensitivity, design and scale-up studies for two-stage coal gasifiers applying a computer code based on the standard k- $\epsilon$ model and the Multi Solid Progress Variable approach. Vicente et al. [18] employed the Eulerian-Eulerian concept in contrast to many other research groups which used the Eulerian-Lagrangian approach. It was shown that the Eulerian-Eulerian concept is suitable to predict the gasification even though the measured values could only be poorly predicted.

For the DP-1 Pressurised Entrained-flow High Temperature Black Liquor Gasifier, Marklund et al. [19, 20] used the CFX code and performed sensi- 
tivity studies of the effect of black liquor physicochemical properties (specific heat) and the gas-phase absorption coefficient on the model performance. It was pointed out that the physicochemical properties did not exert a significant influence on the predictions and that the devolatilization of black liquor (including the release of sulfur) had to be described accurately. Comparison of the predicted and measured temperatures inside the reactor indicated substantial differences. This was attributed to both, simplicity of some submodels and usage of guessed values for parameters to which the predictions were sensitive. In the work of Carlson et al. [21] comparisons of the predictions with gas compositions measured at one point inside the gasifier near the outlet indicated a good agreement. To improve the agreement with measurements one third of the formed methane had to be treated as a non-reactive species.

Silaen and Wang [22] developed an ANSYS Fluent CFD model for a twostage entrained flow coal gasifier and studied in particular the influence of the turbulence model and the turbulent dispersion model parameter. Because the standard k- $\epsilon$ model, the RSM and the SST k- $\omega$ model gave similar results, while the results using $\mathrm{k}-\omega$ model or realizable $\mathrm{k}-\epsilon$ model differed from the other ones, Silaen and Wand applied the standard k- $\epsilon$ model as the base model in their studies. They reduced the default value of the turbulent dispersion model parameter avoiding an overprediction of fuel concentrations at the centerline.

Kumar and Ghoniem $[23,24]$ investigated firstly the influence of the turbulence model on the simulated results of selected test cases for which experimental data were available. Although LES was preferred, it was recommended to use SST k- $\omega$ model due to a shorter computing time. Furthermore, they suggested to increase the default model parameter $C_{L}$ (see Equation 9) 
of the particle dispersion model in ANSYS Fluent. Three different entrained flow gasifiers (BYU EFG and two MHI EFGs) were studied to demonstrate the advantage of the SST k- $\omega$ model over the standard $k-\epsilon$ model. It was pointed out that an unsteady solver was necessary to compute the entrained flow gasification on a very fine mesh.

Abani and Ghoniem [25] considered also the BYU gasifier and performed both RANS simulations using standard k- $\epsilon$ model and Large Eddy Simulations. It was concluded that LES could describe the unsteady flow structures, the mixing, and the particle dispersion inside the BYU gasifier better than RANS simulations. RANS simulations failed to predict the conversion of the larger particles due to their accumulation near the symmetry axis; the radial dispersion was underpredicted. In addition, they overpredicted the mixing and underpredicted the temperature fluctuations in the combustion zone.

Lu and Wang [26] investigated the influence of the radiation model on the overall results of the simulation of a pressurized two stage entrained flow coal gasification. The CFD model of Silaen and Wang [22] was used and specific functions for the absorption coefficient based on Hottel's charts and Zhang's charts were employed. In the sensitivity studies the radiation models available in ANSYS Fluent were tested. It was shown that radiation affected more the inner wall temperatures than the gas temperature predictions and that the P1 model underpredicted the inner wall temperatures although no comparison with experimental data was made. Due to the increase of computing time by using DOM or DTRM and due to the robustness and stability of the P1 model, it was suggested to use the P1 model in future works.

$\mathrm{Ku}$ et al. [27] considered various sorts of biomass and carried out sensitivity analysis concerning operating conditions using OpenFOAM. The results were in accordance with the values measured at the exit of the gasifier. The 
accuracy of the predictions of Gao et al. [28] and $\mathrm{Ku}$ et al. was similar.

To the best of our knowledge, there is no CFD study on entrained flow gasification of biomass which is complemented by a validation using ingasifier measured data. To close this gap, various groups inside and outside the frame of the Helmholtz Virtual Institute of Gasification Technology (HVIGasTech) [29-31] have considered CFD modeling and simulation of entrained flow gasification of glycol in the Research Entrained flow GAsifier (REGA) (see e.g. [30-39]). In a three-part series, we present our current experimental and modeling results concerning gasification of mono ethylene glycol (MEG) which we have used as a model fuel. In the first part [40] an experimental campaign called REGA-glycol-T1 is described. In this paper we report on simulation of the campaign using RANS based CFD. The third paper [41] describes Large Eddy Simulations of the same REGA-glycol-T1 campaign.

\section{Modeling}

\subsection{Modeling the gas-phase flow field}

The gas-phase of the REGA gasifier has been modeled using the Reynolds averaged Navier-Stokes (RANS) approach for the closure of the steady state Navier-Stokes (NS) equations. For the mass and momentum conservation, the RANS approach leads to the following equations:

$$
\begin{aligned}
\nabla(\rho \mathbf{U}) & =\dot{s}_{m} \\
\rho(\mathbf{U} \cdot \nabla) \mathbf{U} & =-\nabla P+\nabla(\mathbf{D}+\mathbf{T})+\rho \mathbf{g}+\mathbf{f}
\end{aligned}
$$

The velocity vector $(\mathbf{U})$, the density $(\rho)$ and the species mass fraction $\left(Y_{i}\right)$ must be interpreted as Favre averaged values. For a Newtonian fluid, the stress tensor (D) can be related, as a first approximation, to the averaged 
velocity gradients, resulting in the Boussinesq approximation. In Cartesian coordinates it can be written in the following form:

$$
\mathbf{D}_{i j}=\mu\left(\frac{\partial U_{i}}{\partial x_{j}}+\frac{\partial U_{j}}{\partial x_{i}}\right)+\delta_{i j}\left(\beta-\frac{2}{3} \mu\right) \frac{\partial U_{l}}{\partial U_{l}}
$$

The turbulent Reynolds stress tensor $\mathbf{T}$ has been calculated using the Reynolds stress model (RSM) [42, 43]. Other three simpler standard models, namely the realizable $\mathrm{k}-\epsilon[44,45]$, standard $\mathrm{k}-\epsilon[44,46]$ and the SST k- $\omega[47,48]$ have also been tested. The source term $\left(\dot{s}_{m}\right)$ in the continuity equation and the force per unit of mass (f) in the momentum equation take care of the exchange of total mass and momentum between the droplets and the gasphase. In the RSM, transport equations for each component of the $\mathbf{T}$ tensor are solved. The pressure $(P)$, the density $(\rho)$, and the temperature $(T)$ are related to each other through the ideal-gas equation of state.

\subsection{Modeling the discrete-phase}

For the simulation of the thermal conversion of the MEG, droplets are described using the Discrete Phase Model (DPM). The DPM assumes that the volume fraction of the liquid-phase is small so that interactions among droplets can be neglected. This assumption is surely not satisfied near the atomizer orifice where the liquid jet is still unbroken and secondary atomization is taking place. The simulation of the atomization process is too expansive to be incorporated into the model therefore the initial conditions (droplets velocities and size distribution) are taken from measurements (see Jacobs et al. [30, 40]).

The dispersion of the liquid-phase is simulated in a Lagrangian frame; for 
each droplet the following equations are solved:

$$
\begin{aligned}
\frac{d \mathbf{x}_{p}}{d t} & =\mathbf{u}_{p} \\
\frac{d \mathbf{u}_{p}}{d t} & =\mathbf{a}_{d}+\left(1-\frac{\rho}{\rho_{p}}\right) \mathbf{g}
\end{aligned}
$$

where $\mathbf{a}_{d}$ and $\mathbf{g}$ are the acceleration due to drag force and the acceleration due to gravity. The droplets are assumed to be spherical, therefore the drag acceleration is written as:

$$
\mathbf{a}_{d}=\frac{18 \mu}{d_{p} \rho_{p}^{2}} \frac{C_{D} R e_{p}}{24}\left|\mathbf{u}_{\text {rel }}\right| \mathbf{u}_{\text {rel }}
$$

where $\mathbf{u}_{\text {rel }}=\mathbf{u}-\mathbf{u}_{p}$ is the relative velocity of the droplets respect to the actual velocity $(\mathbf{u})$ of the gas. The actual velocity of the gas is calculated from the Favre averaged gas velocity $(\mathbf{U})$ adding a random contribution from the turbulent fluctuations:

$$
u_{i}=U_{i}+\xi \sqrt{u_{i}^{\prime 2}}
$$

where $\xi$ is a normally distributed random number. If the assumption of homogeneous turbulence is used, as in the $\mathrm{k}-\varepsilon$ and $\mathrm{k}-\omega$ models, the previous equation is simplified into the following:

$$
\mathbf{u}=\mathbf{U}+\widehat{n} \sqrt{2 k}
$$

where $\widehat{n}$ is a random generated unit vector.

The equations of motion (4) and (5) are solved in a given instance of the turbulence for a characteristic lifetime of the eddy defined by

$$
\tau_{e}=2 C_{L} \frac{k}{\varepsilon}
$$

with the constant $C_{L}=0.15$ for the k- $\varepsilon$ model and $C_{L}=0.3$ for the RSM. In order to increase the accuracy of the model, the equations for each droplet 
are integrated 100 times and the results are averaged before passing them to the solver for the gas-phase.

In Equation (6) the droplet Reynolds number $R e_{p}$ is defined by:

$$
R e_{p}=\frac{\rho d_{p}\left|\mathbf{u}_{\mathrm{rel}}\right|}{\mu}
$$

and the drag coefficient, $\left(C_{D}\right)$, taken from [49]:

$$
C_{D}=a_{1}+\frac{a_{2}}{R e_{p}}+\frac{a_{3}}{R e_{p}^{2}}
$$

The aforementioned model has been originally developed in Sheffield [5052], implemented in the Fluent software and since then it is an integral part of many CFD codes.

\subsection{Species transport equations}

The equation for the Favre averaged mass fraction $\left(Y_{i}\right)$ of each species $(i)$ is written as follow:

$$
\nabla\left(\rho Y_{i} \mathbf{U}\right)=\nabla \mathbf{J}_{i}+\dot{s}_{i}
$$

where the mass transfer flux $\left(\mathbf{J}_{i}\right)$ is given by:

$$
\mathbf{J}_{i}=\rho D_{i, m} \nabla Y_{i}+\mathbf{J}_{t, i}
$$

with $\mathbf{J}_{t, i}$ being the unclosed turbulent mass transfer flux. The source term $\dot{s}_{i}$ takes into account both, the interaction with the fluid-phase and the chemical reactions proceeding in the gas-phase.

\subsection{Energy balance equation}

An equation similar to Equation (12) is written for the total energy $e=$ $h+\frac{U^{2}}{2}-\frac{p}{\rho}$ :

$$
\nabla(\rho \mathbf{U} e)+\nabla \cdot(\mathbf{U} p)=\Phi+\dot{Q}-\nabla \cdot \mathbf{q}+\mathbf{L}
$$


The rate of work done by external forces $(\mathbf{L})$ takes into account the work done during the momentum exchange between the gas-phase and the liquid-phase while $\Phi$ is the dissipation by viscous stress.

The energy flux vector (q) consists of several contributions, namely heat transfer due to conduction $\left(\mathbf{q}_{c}\right)$, turbulent transport $\left(\mathbf{q}_{t}\right)$, multicomponent heat diffusion $\left(\mathbf{q}_{m}\right)$ and heat flux due to concentration gradients $\left(\mathbf{q}_{D}\right)$ (Dofour effect). The thermal conduction is described by the Fourier law:

$$
\mathbf{q}_{c}=-k_{g} \nabla T
$$

where $k_{g}$ is the thermal gas conductivity. The multicomponent heat transfer rate reads:

$$
\mathbf{q}_{m}=\nabla \cdot\left(\sum_{j} h_{j} \mathbf{J}_{j}\right)
$$

The Dofour effect as well as the Soret effect are neglected in this work.

In the above equations the two new unclosed turbulent fluxes, $\mathbf{J}_{t, i}$ and $\mathbf{q}_{t}$, are modeled using the gradient diffusion hypothesis:

$$
\begin{aligned}
\mathbf{J}_{t, i} & =D_{t} \nabla Y_{i} \\
\mathbf{q}_{t} & =k_{t} \nabla h
\end{aligned}
$$

where the turbulent diffusivity $\left(D_{t}\right)$ and the turbulent conductivity $\left(k_{t}\right)$ are introduced. Using these two quantities, it is possible to define an effective diffusivity $\left(D_{e f f}\right)$ and an effective conductivity $\left(k_{e f f}\right)$. The effective thermal conductivity is given by:

$$
k_{e f f}=k_{g}+\frac{c_{p} \mu_{t}}{P r_{t}}
$$

where $k_{g}$, here, is the thermal conductivity of the gas mixture. The default value of the turbulent Prandtl number is 0.85 . Turbulent mass transfer is treated similarly:

$$
D_{e f f, i}=D_{i, m}+\frac{\mu_{t}}{\rho S c}
$$


where $S c$ is the Schmidt number equal to 0.7 .

The thermodynamic properties, namely specific heats, viscosity, thermal conductivity and mass diffusivity, are needed and they are calculated using tabulated fittings of measured values or using the kinetic theory of gases. In particular the specific heats are calculated as a function of the temperatures using polynomials [53] and the molecular viscosity for a pure species is calculated using the Sutherland viscosity law with three coefficients. Thermal conductivity is calculated using the kinetic theory of gases with the help of data for the Lennard-Jones potentials. Diffusivity is calculated using a modification of the Chapman-Enskog formula. The need for a multicomponent diffusion is justified considering that good accuracy is required for the calculation of the evaporation rate of MEG using correlation (26).

The temperature of each droplet is calculated solving the energy balance equation assuming lumped capacitance method $(B i \ll 1)$ :

$$
m_{p} c_{p} \frac{d T_{p}}{d t}=h_{g} A_{p}\left(T_{\infty}-T_{p}\right)+\epsilon_{p} A_{p} \sigma\left(\theta_{R}^{4}-T_{p}^{4}\right)+r_{e v} \frac{d m_{p}}{d t}
$$

where $c_{p}$ represents the specific heat capacity of the droplets, $A_{p}$ the surface area of the droplets, $T_{\infty}$ the local temperature of the gas-phase, respectively. Radiation is taken also into account using the radiation temperature $\theta_{R}$, defined by $\theta_{R}=\left(\frac{G}{4 \sigma}\right)^{1 / 4}$ with $G$ being the total incident radiation; $r_{e v}$ is the specific enthalpy of vaporization for the MEG.

The convective heat transfer coefficient $\left(h_{g}\right)$ is evaluated using the correlation [54]:

$$
N u=\frac{h_{g} d_{p}}{k}=2.0+0.6 \operatorname{Re}_{d}^{1 / 2} \operatorname{Pr}^{1 / 3}
$$

where $d_{p}$ represents the droplet diameter, $k_{g}$ the thermal conductivity of the continuous phase and $\operatorname{Pr}$ is the Prandtl number of the continuous-phase. 
Due to evaporation the diameter of the droplets changes following a $d^{2}$ law:

$$
\rho_{p} \frac{d}{d t} d_{p}=-6 \cdot \dot{m}_{e}
$$

The evaporation rate per unit of surface $\left(\dot{m}_{e}\right)$ is calculated using the following correlation:

$$
\dot{m}_{e}=k_{e} \cdot \ln (1+B)
$$

with $k_{e}$ the mass transfer coefficient and $B$ [55] the mass transfer number that takes into consideration the Stephan flow:

$$
B=\frac{Y_{s}-Y_{\infty}}{1-Y_{s}}
$$

The glycol-vapor mass fraction $Y_{\infty}$ and $Y_{s}$ are evaluated at the bulk and at the surface, respectively. At the surface of the droplet, thermodynamical equilibrium is assumed and the partial pressure of glycol-vapor $\left(p^{\prime}\right)$ equals the saturation pressure: $p^{\prime}=p_{\text {sat }}(T)$. The mass transfer coefficient $\left(k_{e}\right)$ is calculated using a correlation for the Sherwood $(S h)$ number as a function of the Reynolds $\left(R e_{p}\right)$ and the Schmidt number $(S c)$ :

$$
S h=\frac{k_{e} d_{p}}{D_{i, m}}=2.0+0.6 R e_{p}^{1 / 2} S c^{1 / 3}
$$

\subsubsection{Radiative heat transfer}

The variation of the spectral intensity $\left(I_{\eta}\right)$ along an optical path $(s)$ due to absorption, emission, and scattering (both, in- and out-scattering) is described by the radiative transfer equation (RTE):

$$
\frac{\mathrm{d} I_{\eta}}{\mathrm{d} s}=-a_{\eta} \cdot I_{\eta}+a_{\eta} \cdot I_{\eta, \mathrm{b}}-\sigma_{\eta, s} \cdot I_{\eta}+\frac{\sigma_{\eta, s}}{4 \pi} \int_{0}^{4 \pi} I_{\eta}\left(\vec{s}_{i}\right) \cdot \Phi_{\eta}\left(\vec{s}_{i}, \vec{s}\right) \cdot \mathrm{d} \Omega_{i}
$$

232 where $a_{\eta}$ is the gas absorption coefficient, $I_{\eta}$ is the spectral intensity, $\sigma_{\eta, s}$ is the scattering coefficient, and $\Phi_{\eta}$ is the scattering phase function. Index $\eta$ 
emphasizes that the RTE is valid for one single wavenumber $\eta$ only. However, since gas absorption properties and, therefore, the radiation intensity field strongly depend on wavenumber, simplifications for the treatment of gas properties are essential in conjunction with overall CFD calculations. The influence of those simplifications are verified in Section 6.3. Solution of the intensity field, Equation (27), is obtained using a modern form of the discrete ordinates method, e.g. see [56], which is called finite volume method [57, 58]. In this method, the RTE, is solved for a discrete number of solid angles $\Delta \Omega$. Each direction $(i)$ has a weight given by its finite solid angle $\Delta \Omega_{i} / 4 \pi$. In this work, a division of 8 polar angles and 8 azimuthal ones per quadrant is used $(8 \mathrm{x} 8)$, which means that the RTE is solved in $4 \cdot 8 \cdot 8=256$ discrete directions (axis symmetry). Since the mesh used in this work is unstructured, pixelation [58] is used to minimize the control-angle overhang which means that solid angle are further subdivided for integration over solid angle. In this work a pixelation of $4 \times 4$ is used. For more details on the radiation solver, the reader is referred to textbooks $[59,60]$ or the original publications $[57,58]$.

\subsection{Turbulence-chemistry interaction}

Combustion, through heat release, affects the formation and dissipation of turbulence but also the presence of fluctuating fields affects strongly the rate of reactions. The effects of the heat release on the turbulence are believed to be well described by the turbulence models. The temperature rise increases the molecular viscosity, leading to an increase of the dissipation rate $(\epsilon)$. Moreover, in the combustion region, the expansion of the gas causes an increase of the velocity, leading to an increase of the kinetic energy $(k)$. Gradients of density and pressure create an extra source for the turbulence. In this work, the calculation of the species concentration and the interaction between turbulence and chemistry are modeled using two different 
approaches. In the first approach, transport equations for each species are solved together with Eddy Dissipation Concept (EDC) for the turbulencechemistry interaction. The second approach is based on the probability density function (PDF) of the mixture fraction (here denoted $f$ ) coupled with a chemical equilibrium procedure.

\subsubsection{The EDC model}

The species transport approach is coupled with the EDC model ([61]) for the reaction rates. In order to react, reactants must be mixed at the molecular level. The smallest scales (eddies) in the turbulent spectrum are responsible for the mixing at the molecular level. Inside these eddies (called fine structures) the reactants are well mixed and the structure can be viewed as a well-stirred reactor. Inside the fine structures the turbulence has no effect. When the fine structure is destroyed (by the turbulence), then the reacted gas mixture is released into the surrounding fluid.

The characteristic time scale of the fine structure is calculated from a model of turbulent energy cascade:

$$
\tau^{*}=\left(\frac{C_{2}}{3}\right)^{1 / 2} \sqrt{\frac{\mu}{\rho \epsilon}}
$$

and the fine structure mass to the total mass ratio is:

$$
\gamma^{*}=\left(\frac{3 C_{2}}{4 C_{1}^{2}}\right)^{3 / 4}\left(\frac{\mu \epsilon}{\rho k^{2}}\right)^{3 / 4}
$$

Mass transfer between the fine structure and the surroundings is given by:

$$
\dot{m}=\frac{\gamma^{*}}{\tau^{*}}=A\left(\frac{\mu \epsilon}{\rho k^{2}}\right)^{1 / 4} \frac{\epsilon}{k}
$$

with the constant $A$ being a function of the constants $C_{1}$ and $C_{2}$. For these constant it was found empirically that $C_{1}=0.135$ and $C_{2}=0.5$, giving for the constant $A$ the value of 23.66 [61]. 
The source term for species $i$ in Equation (12) is given by:

$$
\dot{s}_{i}=\rho \frac{\gamma^{*}}{\tau^{*}}\left(Y_{i}^{o}-Y_{i}^{*}\right) \xi
$$

In the above equation $Y_{i}^{o}$ is the mass fraction of species $i$ in the surrounding fluid entering the fine structure, and $Y_{i}^{*}$ is the final composition in the fine structure. The factor $\xi$ can be considered to limit the fraction of the fine structure that really reacts. Usually, it is near 1 and in this work its influence is ignored. The composition of the two regions can be related to provide the mean composition in the volume:

$$
Y_{i}=\gamma^{*} \xi Y_{i}^{*}+\left(1-\gamma^{*} \xi\right) Y_{i}^{o}
$$

Combining the last two equations, the rate of combustion can be written in terms of the mean mass fraction and the fine structure mass fractions:

$$
\dot{s}_{i}=\frac{\gamma^{*}}{\tau^{*}}\left(Y_{i}-Y_{i}^{*}\right) \frac{\xi}{1-\gamma^{*} \xi}
$$

\subsubsection{The PDF model}

Alternatively to the Reynolds-averaging source terms and the transport equations for energy and species, a single-point joint probability density function (PDF) can be derived [62]. The PDF, denoted by $\mathcal{P}$, can be considered to be proportional to the fraction of the time that the fluid spends at each species, temperature, and pressure state. The probability function $\mathcal{P}$ has $N+2$ dimensions for $N$ species, temperature, and pressure spaces. When the PDF is known, any thermochemical moment (e.g., the mean temperature, the $R M S$ temperature, the mean reaction rate) can be calculated. The composition PDF transport equation can be derived from the Navier-Stokes equations. In the case of the probability density function for the mixture fraction $f^{*}$, the general PDF Equation can be simplified further because $f^{*}$ 
has no source terms and the dimensionality of the $\mathcal{P}$ is reduced to only three variables: the mixture fraction $(f)$, the temperature $(T)$ and the pressure $(p)$.

Although $\mathcal{P}$ can be evaluated in a lower dimension space, its detailed calculation is still computationally expensive. A less expensive method is to use a presumed PDF. In the present work, the $\beta$-function is used which is mathematically defined as:

$$
\beta_{a, b}\left(f^{*}\right)=C \cdot\left(f^{*}\right)^{a-1}\left(1-f^{*}\right)^{b-1}
$$

where $C$ is the constant that assures the normalization. The two parameters $a$ and $b$ are linked to the first and the second moment of the PDF. If the dimensionality is further reduced by considering $\mathcal{P}$ as a function of the mixture fraction $f$ only, the parameters $a$ and $b$ are calculated using the mean value of mixture fraction $f=\overline{f^{*}}$ and the mixture fraction variance $\sigma_{f}=\overline{\left(f^{*}\right)^{2}}$ :

$$
\begin{aligned}
a & =f\left(\frac{f(1-f)}{\sigma_{f}}-1\right) \\
b & =(1-f)\left(\frac{f(1-f)}{\sigma_{f}}-1\right)
\end{aligned}
$$

The conservation equation for the mean mixture fraction variance, $\left(\sigma_{f}\right)$ is:

$$
\begin{aligned}
& \frac{\partial}{\partial t}\left(\rho \sigma_{f}\right)+\nabla \cdot\left(\rho \mathrm{U} \sigma_{f}\right)= \\
& \quad \nabla \cdot\left(\frac{\mu_{t}}{\sigma_{t}} \nabla \sigma_{f}\right)+C_{g} \mu_{t}\left(\nabla^{2} f\right)-C_{d} \rho \frac{\epsilon}{k} \sigma_{f}
\end{aligned}
$$

The constants $\sigma_{t}, C_{g}$, and $C_{d}$ take the values $0.85,2.86$, and 2.0 , respectively.

The influence of temperature on the chemistry is taken into consideration through the enthalpy $(h)$, calculated together with the flow-field.

From the definition of the PDF it is possible to derive means and variances for all the other variables. The mean of the species (denoted by $\langle\cdot\rangle$ ) and the 
mean of the density are calculated by:

$$
\begin{aligned}
\left\langle Y_{i}(h)\right\rangle & =\int_{0}^{1} \beta\left(f^{*}\right) Y_{i}\left(f^{*}, h\right) d f^{*} \\
\frac{1}{\rho}(h) & =\int_{0}^{1} \beta\left(f^{*}\right) \frac{1}{\rho\left(f^{*}, h\right)} d f^{*}
\end{aligned}
$$

Knowing the PDF and the specific enthalpy $(h)$, the chemical composition can be calculated using a chemical equilibrium procedure for each $f^{*}$.

\subsubsection{Comments concerning turbulence-chemistry interaction modeling}

In modeling gasification processes several requirements must be satisfied by the chemistry-turbulence interaction models. Each turbulence-chemistry modeling approach posses advantages and disadvantages. What generally is required from such a model can be summarized as follows:

1. Good predictions of the micro-mixing process and consequently a good method for accounting for slow-down of chemical reactions due to turbulent mixing;

2. Correct asymptotic behavior predicting chemical equilibrium at large residence times (see below);

3. Usability, in terms of applicability to complex industrial gasification plants.

The first requirement is fulfilled by both above described models, considering that exothermic reactions are expected to be fast and consequently reaction rates are not everywhere kinetically controlled. Both chosen models are able to predict the slow-down of chemical (laminar) rates in turbulent flows. Generally, the description of the turbulent fluctuations and of the mixing provided by a PDF method is more accurate than the one given by the EDC since more details are retained by the PDF description while the EDC describes the turbulent fluctuations based upon two regions only. A drawback 
of the $\beta$-PDF model, in the modeling of the REGA reactor, is its inadequacy of simulating mixing of three streams. In REGA (see [40]) the stream of evaporating glycol is mixed with the gasification medium (oxygen enrichedair) and with recirculated and partially converted syngas. Since evaporation is slower than the entrainment (mixing with the recirculated syngas), even if the recirculation is strong, the inaccuracy introduced should be small. This may not be correct in the near burner region where the atomization process governs the mixing.

The second requirement is related to the need to let the water gas shift reaction (WGSR) reach the equilibrium. In combustion problems, the WGSR is important inside the flame hot spots only. In gasification systems, the WGSR equilibrium is reached at lower temperatures. The PDF method equipped with chemical equilibrium provides a way to reach equilibrium in any conditions however, the EDC does not posses this property. In the EDC, the reaction rates are limited by the local turbulent time scales. Since the standard implementation of EDC is based on quantities locally calculated in each cell, there is no memory of previously achieved molecular mixing and when a local turbulent time scale increases, because of laminarization or natural turbulence decay as in convective regions, the chemical reactions do not have anymore the possibility to reach equilibrium in the gas-phase. As a lemma of this analysis, models based only on turbulent mixing as the Eddy Break Up model [63], or the mixed-is-burned model, not implementing chemistry, do not reproduce accurately the reaction rates and they are inadequate for gasification modeling.

The advantage of the species transport model coupled with the EDC manifests itself in its adaptability to complex geometrical arrangements pertinent in industrial applications. The implementation of the PDF method 
discussed here is based on one single mixture fraction. One mixture fraction is enough for the simulation of the gasification of pure MEG, as in this paper, but it is not enough for the simulation of, for example, slurry (oil + char) gasification. Increasing the number of mixture fractions is mathematically feasible but the resulting model requires more computational power.

A drawback of the PDF model implemented for this work is the use of chemical equilibrium in regions where finite rate chemistry plays a role.

\subsection{Glycol decomposition and gas-phase reactions}

The chemical reactions used in the EDC can be written in the following way:

$$
\sum_{r}^{N} \nu_{r} M_{r} \leftrightarrows \sum_{p}^{N} \nu_{p} M_{p}
$$

where the index $r$ refers to the reactants and $p$ to the products. The forwards and the backwards reaction rates are written generally in the following way:

$$
\frac{1}{\nu_{r}} \frac{d\left[M_{r}\right]}{d t}=-\sum_{j} k_{j, f} \prod_{\text {forward }}\left[M_{f}\right]^{a_{f}}+\sum_{j} k_{j, b} \prod_{\text {backward }}\left[M_{b}\right]^{a_{b}}
$$

The rate constants are expressed using the Arrhenius form:

$$
k_{f, b}=A T^{b} \exp \left(-\frac{E}{R T}\right)
$$

In the previous equations all the concentrations are expressed in $\frac{\mathrm{kmol}}{\mathrm{m}^{3}}$ while the time is in second. The unit for the Arrhenius rate constant $A$ changes accordingly to each reaction. The following reaction sequence is considered:

1. thermal decomposition of MEG molecules. MEG vapor decomposes into a gas containing $\mathrm{CO}, \mathrm{CO}_{2}, \mathrm{CH}_{4}, \mathrm{H}_{2}, \mathrm{H}_{2} \mathrm{O}$

$$
R 1: \mathrm{C}_{2} \mathrm{H}_{6} \mathrm{O}_{2} \rightarrow \mathrm{CO}, \mathrm{CO}_{2}, \mathrm{CH}_{4}, \mathrm{H}_{2}, \mathrm{H}_{2} \mathrm{O}
$$


2. reactions with $\mathrm{O}_{2}$ :

b1) partial oxidation of MEG-vapor in gas-phase

$$
R 2: \mathrm{C}_{\mathrm{x}} \mathrm{H}_{\mathrm{y}} \mathrm{O}_{\mathrm{z}}+\zeta \mathrm{O}_{2} \rightarrow \zeta_{1} \mathrm{CO}+\zeta_{2} \mathrm{H}_{2}+\zeta_{3} \mathrm{CO}_{2}+\zeta_{4} \mathrm{H}_{2} \mathrm{O}
$$

b2) oxidation of decomposition products and syngas components

$$
\begin{aligned}
& R 3: \mathrm{H}_{2}+0.5 \mathrm{O}_{2} \rightarrow \mathrm{H}_{2} \mathrm{O} \\
& R 4: \mathrm{CO}_{2}+0.5 \mathrm{O}_{2} \rightarrow \mathrm{CO}_{2} \\
& R 5: \mathrm{CH}_{4}+0.5 \mathrm{O}_{2} \rightarrow \mathrm{CO}+2 \mathrm{H}_{2}
\end{aligned}
$$

3. reforming / gasification reactions.

$$
\begin{aligned}
& R 6: \mathrm{CO}+\mathrm{H}_{2} \mathrm{O} \rightleftarrows \mathrm{CO}_{2}+\mathrm{H}_{2} \\
& R 7: \mathrm{CH}_{4}+\mathrm{H}_{2} \mathrm{O} \rightleftarrows \mathrm{CO}+3 \mathrm{H}_{2}
\end{aligned}
$$

Two global kinetics mechanisms have been used. The HVI1 mechanism (see Table 1) has been derived using both the detailed mechanism of Hafner et al. [32] for glycol decomposition and the GRI3.0 mechanism [64] for oxidation of $\mathrm{C} 1$ to $\mathrm{C} 3$ hydrocarbons. The second mechanism, named here as extended-Jones-Lindstedt (eJL) mechanism (see Table 2), has been composed by adding the first two reactions (eJL-1 and eJL-2), derived from Hafner et al. [32] mechanism, into the known Jones-Lindstedt mechanism [13].

In the original paper [13] two equations for the eJL-4 rate have been given. In this work we use:

$$
\frac{d\left[\mathrm{H}_{2}\right]}{d t}=-k_{4} \cdot \frac{\left[\mathrm{H}_{2}\right]^{0.5}\left[\mathrm{O}_{2}\right]^{2.25}}{\left[\mathrm{H}_{2} \mathrm{O}\right]}
$$

since it is supposed to be more accurate than the other one [13]. One should realize that the original JL mechanism has been developed for methane combustion in lean mixtures, in other words, not for substoichiometric oxidation. 


\begin{tabular}{llccc}
\hline \hline & Reaction & $\mathrm{A}$ & $\mathrm{b}$ & $\mathrm{E} / 10^{8}$ \\
& & kmol,meter,second & $\frac{\mathrm{J}}{\mathrm{kmol}}$ \\
\hline $\mathrm{HVI1}-1$ & $4 \mathrm{C}_{2} \mathrm{H}_{6} \mathrm{O}_{2} \rightarrow 9 \mathrm{H}_{2}+7 \mathrm{CO}+\mathrm{H}_{2} \mathrm{O}+\mathrm{CH}_{4}$ & $9.31 \cdot 10^{13}$ & 0.0 & 2.684 \\
$\mathrm{HVI1}-2$ & $\mathrm{CH}_{4}+1 / 2 \mathrm{O}_{2} \rightarrow \mathrm{CO}+2 \mathrm{H}_{2}$ & $1.5811 \cdot 10^{14}$ & 0.0 & 2.512 \\
$\mathrm{HVI1}-3$ & $\mathrm{CO}+1 / 2 \mathrm{O}_{2}+\mathrm{H}_{2} \mathrm{O} \rightarrow \mathrm{CO}_{2}+\mathrm{H}_{2} \mathrm{O}$ & $3.1623 \cdot 10^{11}$ & 0.0 & 1.256 \\
$\mathrm{HVI1}-4$ & $\mathrm{H}_{2}+1 / 2 \mathrm{O}_{2} \rightarrow \mathrm{H}_{2} \mathrm{O}$ & $2.8464 \cdot 10^{14}$ & 0.0 & 2.592 \\
$\mathrm{HVI1}-5$ & $\mathrm{CH}_{4}+\mathrm{H}_{2} \mathrm{O} \rightleftarrows \mathrm{CO}+3 \mathrm{H}_{2}$ & $1.7 \cdot 10^{10}$ & 0.0 & 2.300 \\
HVI1-6 & $\mathrm{CO}+\mathrm{H}_{2} \mathrm{O} \rightleftarrows \mathrm{H}_{2}+\mathrm{CO}_{2}$ & $8.5 \cdot 10^{9}$ & 0.0 & 2.040 \\
\hline
\end{tabular}

However, the mechanism has been frequently used $[6,20,21,24,65,66]$ in modeling of entrained flow gasification of a variety of fuels beginning with coal [65] and ending up with black liquor [20, 21] since there are hardly any other mechanisms available. Thus, the objective is to examine applicability of the eJL mechanism to the REGA-glycol-T1 gasification experiment.

The rate of MEG-vapor decomposition (reactions HVI1-1 and eJL-1) is also calculated using the EDC. In this case the EDC does not consider the mixing of different reactants (not needed for this kind of reaction) but takes into account the heating up of the MEG due to the turbulent mixing. With the assumption of the Lewis number equal to unity, the mathematical expression for the reaction rate does not differ from the one of other reactions. When the EDC is used a direct integration of the rate equations inside the fine structures has been adopted. Techniques of using tabulated values for the chemistry (for example the ISAT table) has not been used in order to avoid the introduction of extra inaccuracies into the calculations. 


\begin{tabular}{llccc}
\hline \hline & Reaction & $\mathrm{A}$ & $\mathrm{b}$ & $\mathrm{E} / 10^{8}$ \\
& & $\mathrm{kmol}$,meter,second & $\frac{\mathrm{J}}{\mathrm{kmol}}$ \\
\hline eJL-1 & $4 \mathrm{C}_{2} \mathrm{H}_{6} \mathrm{O}_{2} \rightarrow 9 \mathrm{H}_{2}+7 \mathrm{CO}+\mathrm{H}_{2} \mathrm{O}+\mathrm{CH}_{4}$ & $9.31 \cdot 10^{13}$ & 0.0 & 2.684 \\
eJL-2 & $\mathrm{C}_{2} \mathrm{H}_{6} \mathrm{O}_{2}+\mathrm{O}_{2} \rightarrow 2 \mathrm{CO}+2 \mathrm{H}_{2} \mathrm{O}+\mathrm{H}_{2}$ & $4.3975 \cdot 10^{10}$ & 0.0 & 1.256 \\
eJL-3 & $\mathrm{CH}_{4}+1 / 2 \mathrm{O}_{2} \rightarrow \mathrm{CO}+2 \mathrm{H}_{2}$ & $4.4 \cdot 10^{11}$ & 0.0 & 1.256 \\
eJL-4 & $2 \mathrm{H}_{2}+\mathrm{O}_{2} \rightleftarrows 2 \mathrm{H}_{2} \mathrm{O}$ & $2.5 \cdot 10^{16}$ & -1 & 1.6747 \\
eJL-5 & $\mathrm{CH}_{4}+\mathrm{H}_{2} \mathrm{O} \rightarrow \mathrm{CO}+3 \mathrm{H}_{2}$ & $3.0 \cdot 10^{8}$ & 0.0 & 1.256 \\
eJL-6 & $\mathrm{CO}+\mathrm{H}_{2} \mathrm{O} \rightleftarrows \mathrm{CO}_{2}+\mathrm{H}_{2}$ & $2.75 \cdot 10^{9}$ & 0.0 & 0.838 \\
\hline
\end{tabular}

Table 2: The extended Jones-Lindstedt (eJL) mechanism for MEG gasification

\section{Inlet and boundary conditions for REGA-glycol-T1 campaign}

The REGA-glycol-T1 experiment has been simulated using a 2D axisymmetric solver with a discretization of the computational domain using roughly $10^{5}$ unstructured cells. Mesh sensitivity has been performed and computational runs using structured meshes have also been carried out. The number of cells has been determined by the accuracy needed inside the flame where steep gradients are present (cell size $\simeq 0.1 \mathrm{~mm}$ ). The inputs of the model for REGA-glycol-T1 experimental run (see [40]) are summarized in Table 3.

\begin{tabular}{llcc}
\hline MEG & $\dot{m}_{M E G}$ & 12.56 & $\frac{\mathrm{kg}}{\mathrm{h}}$ \\
Nitrogen & $\dot{m}_{N_{2}}$ & 9.06 & $\frac{\mathrm{kg}}{\mathrm{h}}$ \\
Oxygen & $\dot{m}_{O_{2}}$ & 9.67 & $\frac{\mathrm{kg}}{\mathrm{h}}$ \\
TOTAL & & 31.29 & $\frac{\mathrm{kg}}{\mathrm{h}}$ \\
\hline
\end{tabular}

Table 3: Inputs for the simulations of the REGA-glycol-T1 campaign (see Table A1 in [40])

424

Both the air infiltrating the reactor and the nitrogen purge (see [40]) are injected together with the atomizing medium, resulting in a gas flow of 
$18.73 \frac{\mathrm{kg}}{\mathrm{h}}$. The oxygen represent then $0.516 \%$ mass fraction $(0.483 \%$ mole fraction) of the total gas input into the reactor.

The walls of the REGA has been electrically heated. For the heating elements a fixed temperature of $\vartheta_{h e}=1200^{\circ} \mathrm{C}$ has been assumed. The heating elements are placed inside the lateral wall at a depth of $\delta_{w}=50 \mathrm{~mm}$, and the heat transfer through this layer has been calculated using the Fourier law for a cylindrical wall:

$$
\dot{q}_{w}=2 \pi k_{w} \frac{T_{h e}-T_{w}}{\ln R_{2} / R_{1}}
$$

with $\dot{q}_{w}$ the specific heat flux through the wall, $k_{w}=2.5 \frac{\mathrm{kW}}{\mathrm{mK}}$ the thermal conductivity of the refractory material, $T_{w}$ the temperature of the internal surface and $R_{1}$ and $R_{2}$ are appropriate radii.

The no slip velocity condition is assumed at the walls. This condition creates a boundary layer that requires fine cells near the walls to be adequately resolved. To avoid the exact solution of the near wall effects and consequently minimize the cell number requirement, the wall function approach is used. In the simulations, the smooth regime is always used, neglecting roughness effects. Since in the performed simulations the wall $y^{+}$is smaller then 30 the two layer model where the linear viscous region is resolved together with the logarithmic turbulent region and a blending function is used [67]. Similar approach using a law-of-the-wall has been used also to resolve the boundary layer for the enthalpy and for the species.

\subsection{Inlet conditions for the spray modeling}

The MEG droplets diameter distribution has been taken from measurements [40] and fitted into the Rosin-Rammler function (see Figure 1). In the figure both mass based and volume based distributions are presented. The parameters for the mass based Rosin-Rammler distribution take values of 
$D_{\text {mean }}=100.9 \mu m$ and $n=1.776$. The volume based distribution (Function Gamma in Figure 1) is used in radiation calculations presented in Section 6.4. Droplets are injected with a velocity of $U=10 \frac{\mathrm{m}}{\mathrm{s}}$ with injection directions distributed uniformly in a cone of $\alpha=10^{\circ}$ half angle.



Figure 1: Fitting of the droplet diameter distributions

\section{Results}

Figure 2 shows the calculated stream lines, for the HVI1 chemistry model in the upper part, the extended JL model in the middle (both combined with the EDC) and for the PDF model (combined with equilibrium) in the lower part; the RSM has been used for turbulence. The near burner region shows a strong outer recirculation zone where the syngas is brought back to the burner and mixed with both the oxygen enriched-air (the gasification medium) and the glycol spray issued from the burner. All the models predict qualitatively the same pattern with similar figures for the total recirculated 
mass. The recirculation predicted by the HVI1 model has a strength of $130 \frac{\mathrm{kg}}{\mathrm{h}}$, corresponding to about 7 times the amount of the enriched-air injected into the reactor (about 4 times the total mass flow injected into the reactor), and it extends up to $z=840 \mathrm{~mm}$ distance from the burner. The extended JL model predicts the length of the recirculation zone to be $910 \mathrm{~mm}$. The PDF model predicts a stronger recirculation zone with a strength of $135 \frac{\mathrm{kg}}{\mathrm{h}}$ and a $800 \mathrm{~mm}$ length. The predictions of the PDF model differ also in the region downstream of the recirculation zone, where the stream lines are more open than in the predictions of the EDC based models.

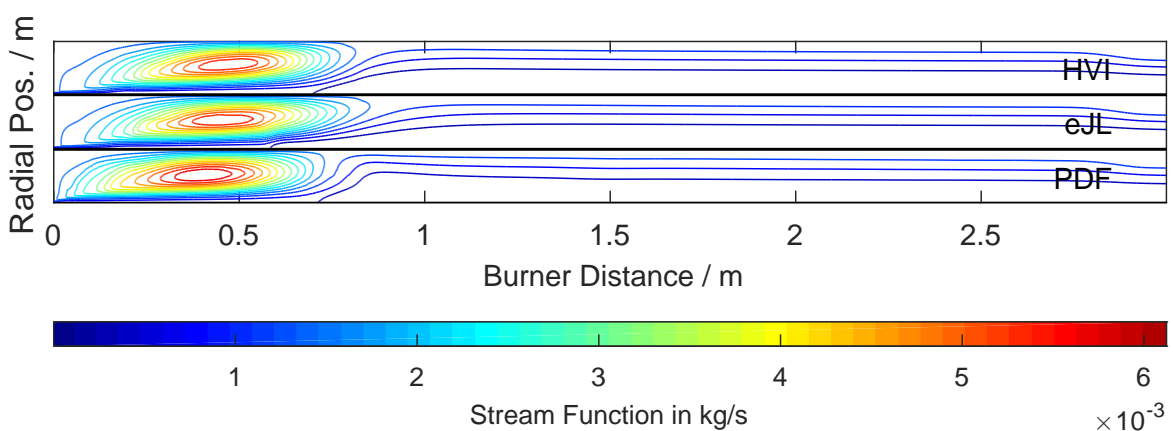

Figure 2: Streamlines predicted by three chemistry models (RSM used for turbulence)

The measurements [40] have been taken in radial direction at two distances from the burner, at $z=300 \mathrm{~mm}\left(z_{1}\right)$ and at $z=680 \mathrm{~mm}\left(z_{2}\right)$ and along the reactor axis. Figure 3 shows contours of the CFD-calculated temperature (Bottom) and the temperature profile along the axis (Top). The good agreement, for all the calculations presented, is an indication of the correctness of the adopted thermal boundary conditions.

In Figure 4 the gas temperatures (left) and the composition (right) are shown at five distances from the burner. All the models show the same general features while differences appear in details. Up to $150 \mathrm{~mm}$ from the 
burner, a cold (thin) core is formed in the middle of the reactor, where glycol droplets are present. Around this cold core a thin (hot) flame is predicted by all the models. Both EDC models show a similar flame structure with the eJL model predicting a longer flame while the HVI1 model predicting a slightly hotter region. The predictions of the PDF model are substantially different in the first $200 \mathrm{~mm}$ from the burner. The mixing between the streams is quicker and it is accomplished within the first $50 \mathrm{~mm}$ from the burner (for both runs using the EDC model a figure of $100 \mathrm{~mm}$ is applicable). As a consequence of the faster mixing and the chemical equilibrium assumption, ignition takes place very close to the burner, at the outer edge of the oxygen enriched-air jet. Figure 3 shows clearly the absence of a cold (conical) region in the PDF calculations. An immediate ignition of glycol-vapor results in a high temperature region also on the axis and this high temperature drives further evaporation (endothermic process) with a subsequent decrease in temperature, clearly seen in Figure 3.

The maximum temperature predicted by the HVI1 model is $T_{\max }=2867$ $\mathrm{K}$ while the eJL model predicts $T_{\max }=2775 \mathrm{~K}$. Both temperatures are high for the absence of radicals in the mixture. Inside the flame, in the first $100 \mathrm{~mm}$ from the burner, the PDF model, due to the coupling with chemical equilibrium calculations, predicts up to $2 \%$ radicals, not taken into consideration in the global mechanisms. As a consequence, the PDF model predicts the maximum temperature of $T_{\max }=2497 \mathrm{~K}$ which is substantially lower than the predictions of the other two models.

From the comparisons presented in Figure 4, it is possible to see that both EDC models predict very accurately the temperature and composition of the gas at $z_{2}=680 \mathrm{~mm}$. The HVI1 mechanism slightly overpredicts the methane concentration at $z_{2}=680 \mathrm{~mm}$, while at traverse $z_{1}=300 \mathrm{~mm}$ the 

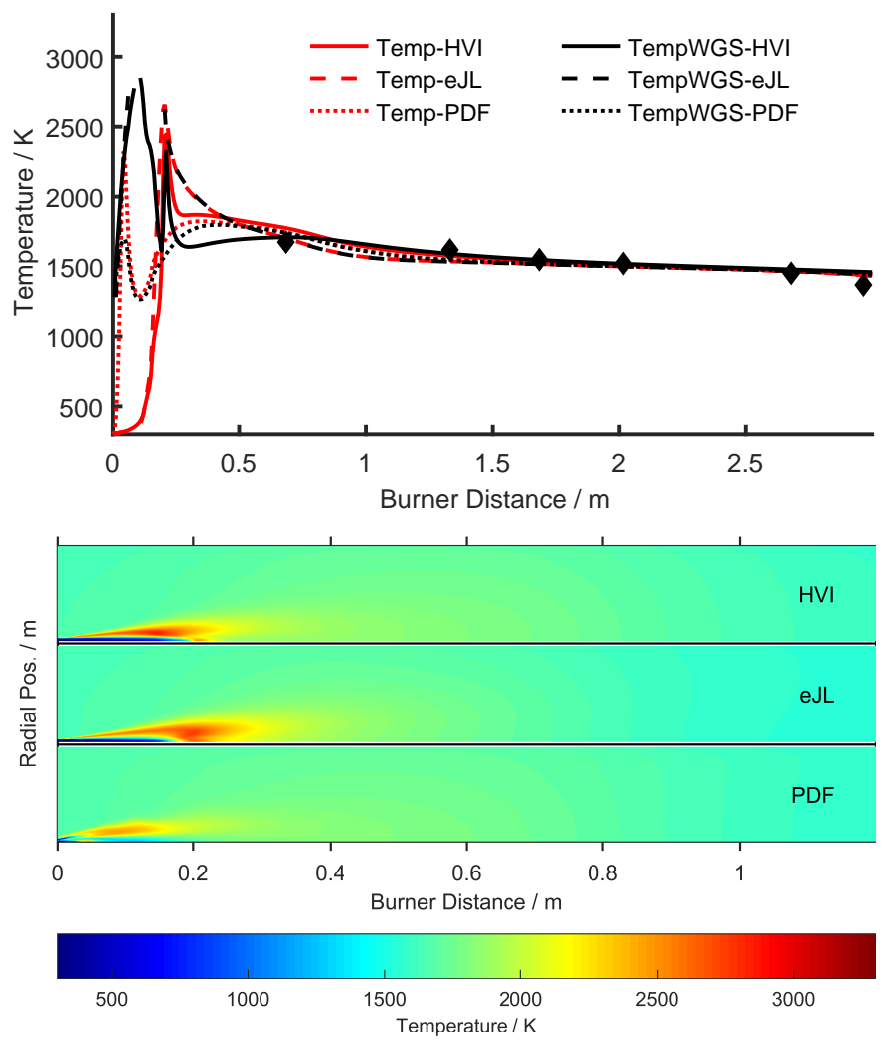

Figure 3: Top: Measured and predicted gas temperature along the gasifier axis. Bottom: raster plot of the CFD-calculated temperatures

predictions are very accurate. The temperatures are well reproduced by all the calculations. The eJL mechanism predicts higher temperatures on the axis while the species concentrations are not as flat as the measurements indicate. It is worthy noticing that the extended JL mechanism does not reproduce correctly the $\mathrm{CO}$ to $\mathrm{CO}_{2}$ ratio near the axis: the measurements indicate higher carbon monoxide than carbon dioxide concentrations while the extended JL shows the opposite. This mechanism predicts a longer flame and at $300 \mathrm{~mm}$ traverse the gas composition reflects more combustion than gasification. 

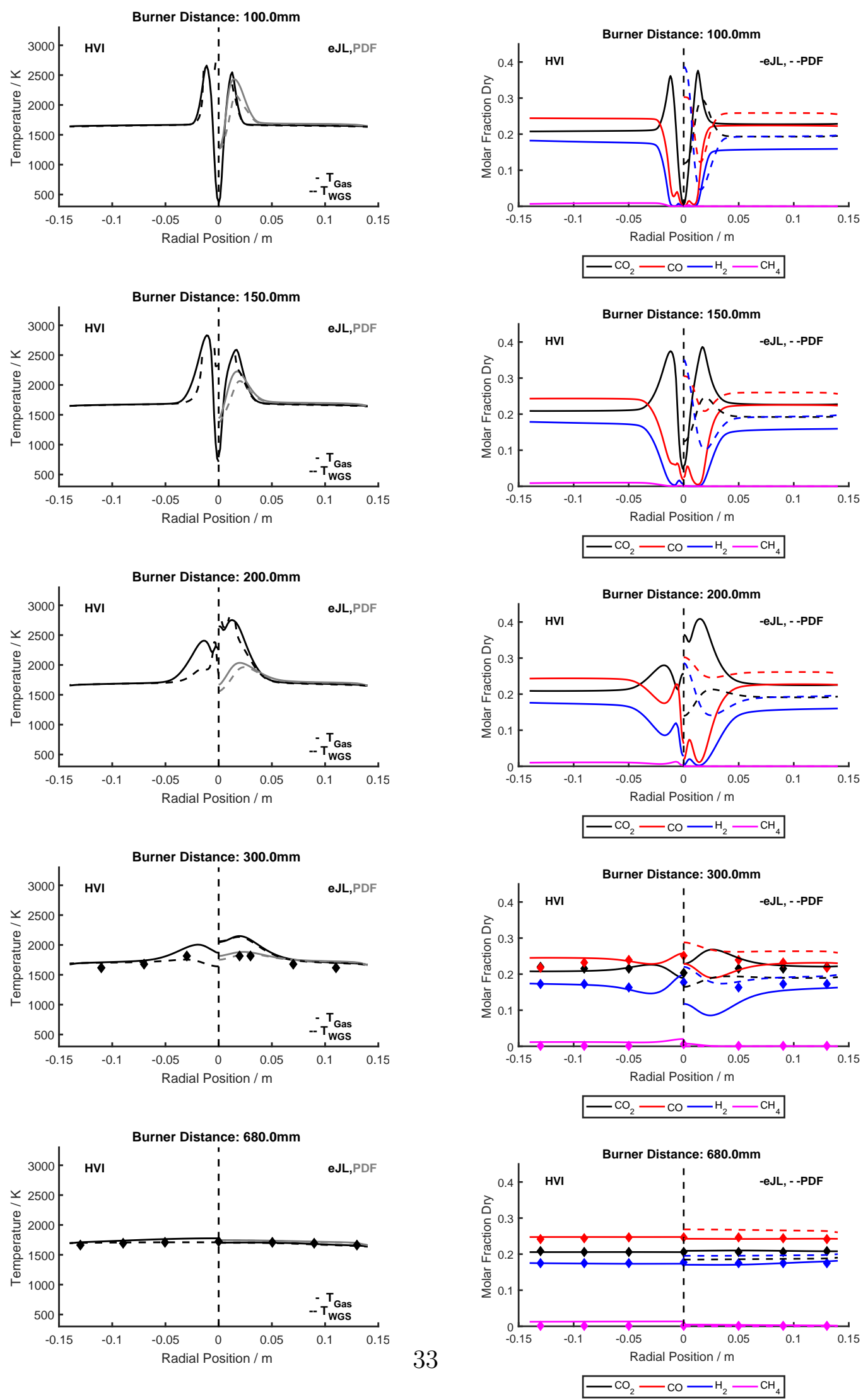

Figure 4: Temperature (Left) and Composition (Right) radial profiles. 

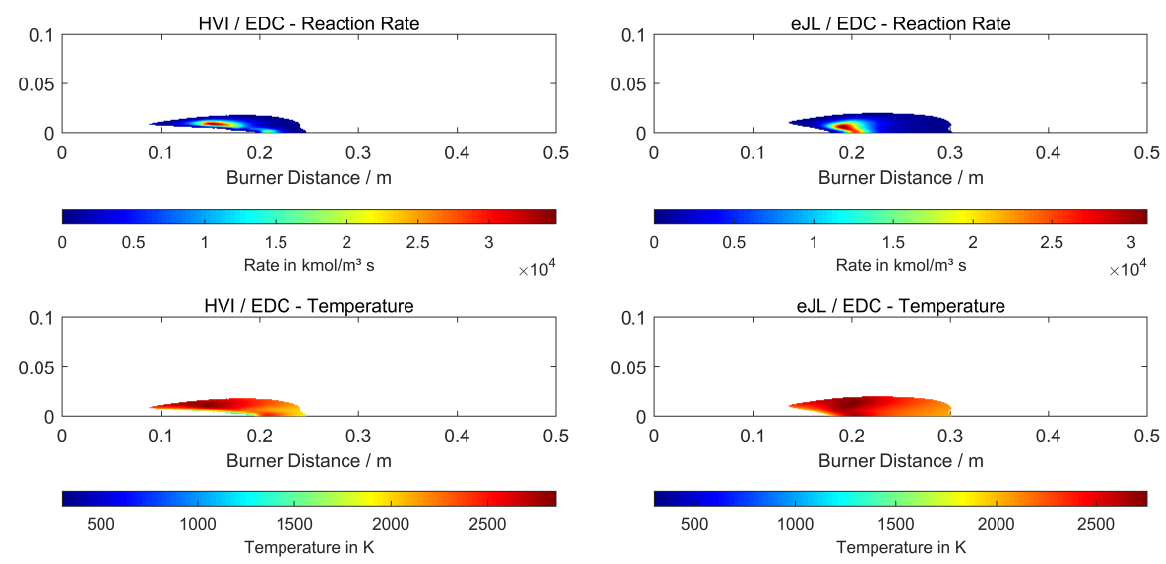

Figure 5: Glycol-vapor decomposition rates: $M E G \rightarrow C O+\mathrm{H}_{2}+\mathrm{H}_{2} \mathrm{O}+\mathrm{CH}_{4}$. The contours are colored by reaction rate (Top) and by gas temperature (Bottom)

\section{Discussion}

\subsection{Structure of the reaction zones}

In Figure 4 the radial profiles of temperature and the species concentration are presented at several traverses namely at $z=100 \mathrm{~mm}, z=150$ $\mathrm{mm}, z=200 \mathrm{~mm}, z=300 \mathrm{~mm}, z=680 \mathrm{~mm}$. The temperature and the concentrations in the last two traverses have been used previously for the validation of the model. The results in the first three traverses, even if no measurements could have been done, will be used to infer the structure and the length of the reaction zone.

Both models show that in the recirculation zone no chemical reactions are taking place. While the chemical composition of the flame is similar, differences are observable at $z=200 \mathrm{~mm}$ where, for the HVI1 model, the oxidation zone is completed while, for the eJL mechanism, it is still going on.

Figure 5 shows the contours of the glycol-vapor decomposition rates (in $\left.\frac{\mathrm{kmol}}{\mathrm{m}^{3} \mathrm{~s}}\right)$; the contours are clipped with a $1 \%$ iso-line of maximum value. The glycol-vapor decomposition reaction (HVI1-1 and eJL-1) is the same in both 
HVI1 and eJL mechanisms. Therefore the characteristics of the MEG decomposition are similar in both simulations. The decomposition is quick and confined to a small region shown in Fig 5. The simulations using the HVI1 mechanism show a more elongated glycol decomposition region with a maximum decomposition rate around $z=150 \mathrm{~mm}$, at a temperature of $T \simeq 1200 \mathrm{~K}$ with most of the decomposition occurring well above $T \simeq 2000$ $\mathrm{K}$ (up to $T \simeq 2800 \mathrm{~K}$ ). Around $10 \%$ of oxygen is present at the onset of the decomposition. The extended JL mechanism predicts a more concentrated decomposition region at around $z=200 \mathrm{~mm}$ starting at much higher temperatures of $T \simeq 1800 \mathrm{~K}$ up to a maximum temperature of $T \simeq 2800 \mathrm{~K}$. Oxygen is still present with a concentration around $20 \%$, which is higher than in the case of the HVI1 mechanism. Both mechanisms predict no glycol decomposition in the close vicinity of the MEG injection.

In the eJL mechanisms glycol-vapor can be oxidized by $\mathrm{O}_{2}$ (reaction eJL2 ). The calculations show that even if oxygen is present and the temperature is high enough at the onset of the MEG decomposition region, the influence of the oxygen is negligible. Only a small fraction of the glycol-vapor (2\%) reacts directly with oxygen; most of the glycol (98\%) is decomposed following the $\mathrm{R} 1$ reaction (HVI1-1 and eJL-1).

The methane created by the glycol decomposition can react further either with oxygen or with water-vapor or both. The contour plot of rate with water-vapor is presented in Figure 6. In the case of the eJL mechanism, $\mathrm{CH}_{4}$ reacts quickly with oxygen and then later, slower, with water. At the outlet of the reactor all the methane has been decomposed and no methane is recirculated back into the the MEG jet. Using the HVI1 mechanism, the overall conversion of methane is slower and at the REGA outlet $0.06 \frac{\mathrm{kg}}{\mathrm{h}}(0.2 \%$ by mass, wet) are still present. For comparison, $\mathrm{CH}_{4}$ is created during the 

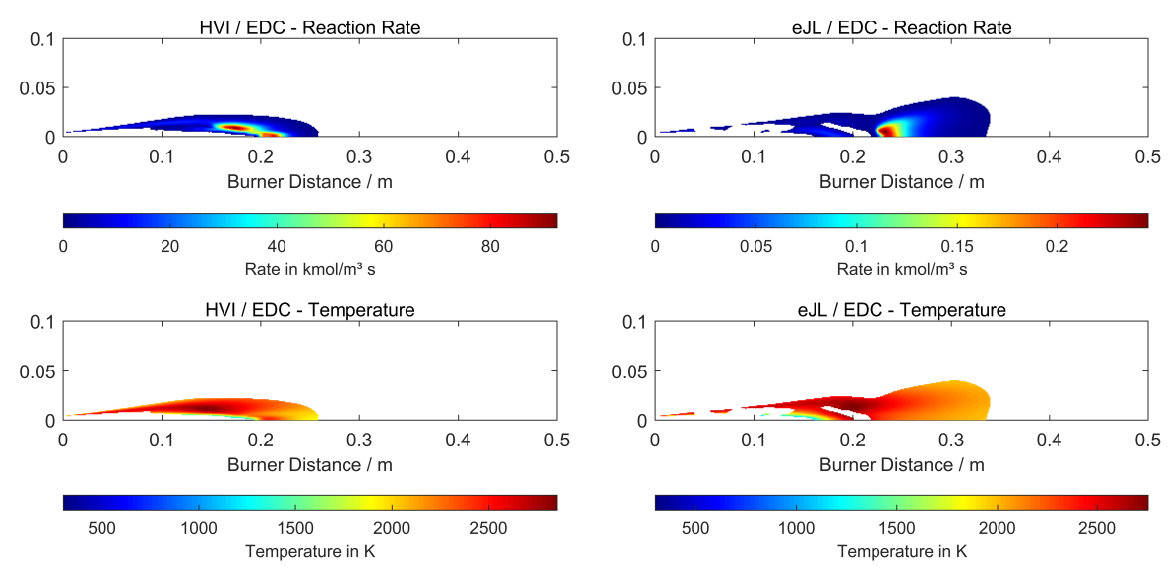

Figure 6: Rates of reaction $\mathrm{CH}_{4}+\mathrm{H}_{2} \mathrm{O} \rightarrow \mathrm{CO}+3 \mathrm{H}_{2}$. The contours are colored by reaction rate (Top) and by gas temperature (Bottom)

glycol-vapor decomposition at a rate of $0.8 \frac{\mathrm{kg}}{\mathrm{h}}$. The methane remains then in the recirculation zone and reacts with the oxygen and the water-vapor present in the thin flame where the temperature is high. Therefore, the region in which methane reacts with water-vapor is more extended, if eJL mechanism is used.

The methane reaction with oxygen is in both mechanisms quicker than the reaction with water-vapor and the oxidation predicted by the HVI1 mechanism is much quicker than the one predicted by the JL mechanism. For both mechanism as soon as methane and oxygen are present together, they react quickly. For the HVI1 mechanism the oxidation of methane is present all over the thin flame while for the extended JL only at the tip of the flame. This is linked to the previous observation that in the calculations with the eJL mechanism no $\mathrm{CH}_{4}$ reach the base of the flame due to quicker reactions with water-vapor.

In the thin flame region the combustible gas entrained from the recirculation zone is at stoichiometric conditions while the oxygen is present in the atomization medium. In this thin flame region, combustion of carbon monox- 
ide and hydrogen takes place in parallel with the oxidation of methane.

From the above discussion it is evident that the oxidation reactions are responsible for the small thin flame formed at the top of the reactor, while the glycol decomposition together with the homogeneous WGSR determine the syngas composition.

Figures 3 and 4 show the WGSR equilibrium temperature introduced in Part I [40], together with the gas temperature. The WGSR equilibrium temperature is lower than the gas temperature mainly in the gasification zone. It is to infer that the eJL mechanism leads quicker to equilibrium than the HVI1 mechanism.

The main gaseous species are generated by thermal cracking (reaction R1), and the concentration of MEG, still in the liquid-phase, is shown in Figure 7. All three models predict presence of liquid-glycol downstream the main oxidation region.

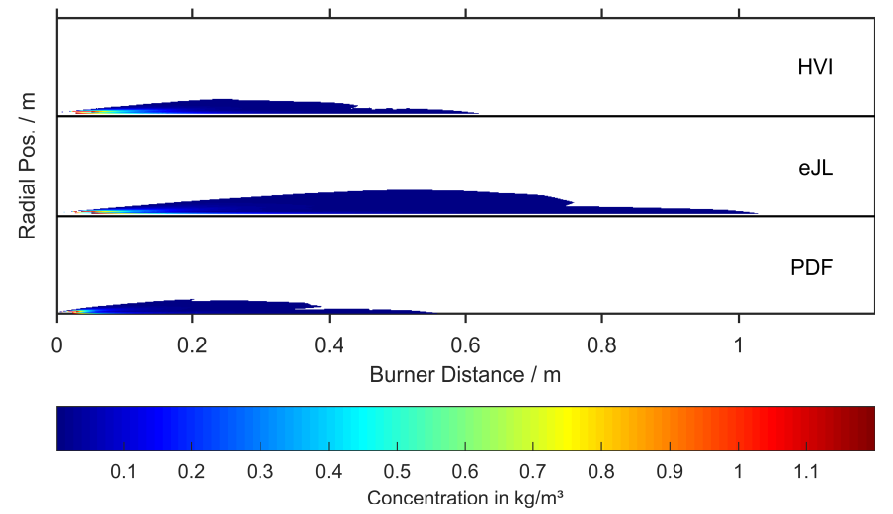

Figure 7: MEG concentration in liquid-phase

Evaporation histories of four different droplet sizes (namely $20 \mu \mathrm{m}, 50$ $\mu \mathrm{m}, 100 \mu \mathrm{m}$ and $200 \mu \mathrm{m})$ are shown in Figure 8. The simulation with the eJL mechanism predicts twice longer evaporation times explaining then the difference in the liquid concentrations already seen in Figure 7. In Equation 

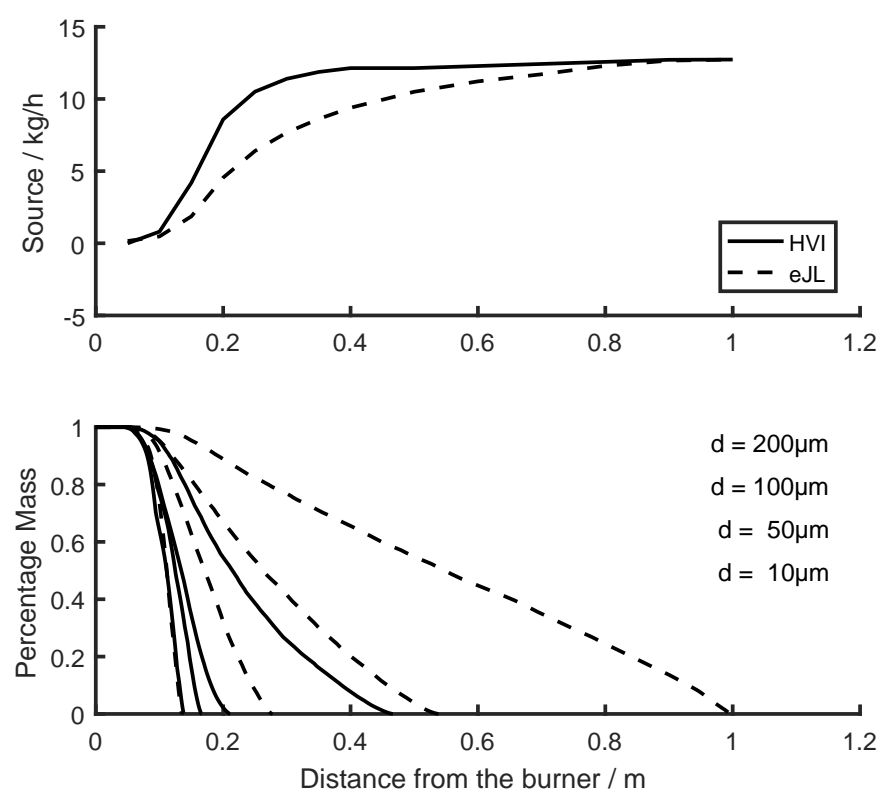

Figure 8: (Top) Mass of evaporated glycol (integrated over reactor cross-section) as a function of the axial distance from the burner; complete evaporation at $12.56 \mathrm{~kg} / \mathrm{h}$ (Bottom) Evaporation histories of droplets of various diameters: $d_{p}=200 \mu \mathrm{m}, d_{p}=100 \mu \mathrm{m}$ $d_{p}=50 \mu \mathrm{m}$ and $d_{p}=20 \mu \mathrm{m}$

(24), to a first order, the evaporation rate is a function of the difference between the saturated pressure (function of the droplet temperature only) and the partial pressure of glycol-vapor. In the gasification region the concentration of MEG in the vapor-phase is for the simulation with the eJL mechanism twice larger than those calculated by the HVI1 mechanism. The rate for the MEG decomposition is described in both models using the same expression, but the lower gas temperature calculated using the eJL mechanism is responsible for the aforementioned difference.

\section{Sensitivity Analysis}

A sensitivity analysis has been performed in order to identify the key sub-models and model coefficients affecting the predictions. 


\subsection{Turbulence models}

The standard k- $\epsilon$ model, the realizable $\mathrm{k}-\epsilon$ and the SST k- $\omega$ have been used in place of the more advanced RSM.

It is recognized that the standard $\mathrm{k}-\epsilon$ model is weaker than other, more advanced turbulence models, in predicting accurately the spread of free round (and planar) jet. Both the realizable version of the $\mathrm{k}-\epsilon$ and the $\mathrm{k}-\omega$ model are superior in predicting this kind of flow structure.

When various turbulence models are applied to the REGA reactor, most of the differences can be seen in the flow-field only, as shown in Figure 9. For all the simpler models the strength of the recirculation increases from $\dot{m}=130$ to $\dot{m}=144 \frac{\mathrm{kg}}{\mathrm{h}}$; in the case of the standard $\mathrm{k}-\epsilon$ model a wider jet is predicted, as shown in Figure 9 (Left). Despite of these velocity differences the composition of the gas-phase changes only slightly as presented in the same figure (Right). This effect can be understood when comparing the time scale of the small eddies $\tau^{*}$ (see Equation 28) and the fraction of the fine structure $\gamma^{*}$ (see Equation 29). Both quantities are functions of the turbulent energy $(\mathrm{k})$ and the dissipation rate $(\epsilon)$ and the differences inside both reaction zones are about $10 \%$. If the goal of the simulations is to correctly predict the chemical composition of the syngas, the choice of the turbulence model is irrelevant.

\subsection{Droplets initial conditions}

The results of the calculations are sensitive to changes in quantities related to the droplets. The diameter distribution, the momentum of the droplets and the properties of the liquid MEG should be known with a good accuracy.

The diameter distribution has been changed, adopting a distribution with a twice bigger mean diameter $d_{\text {mean }}=200 \mu \mathrm{m}$, and a second distribution with 

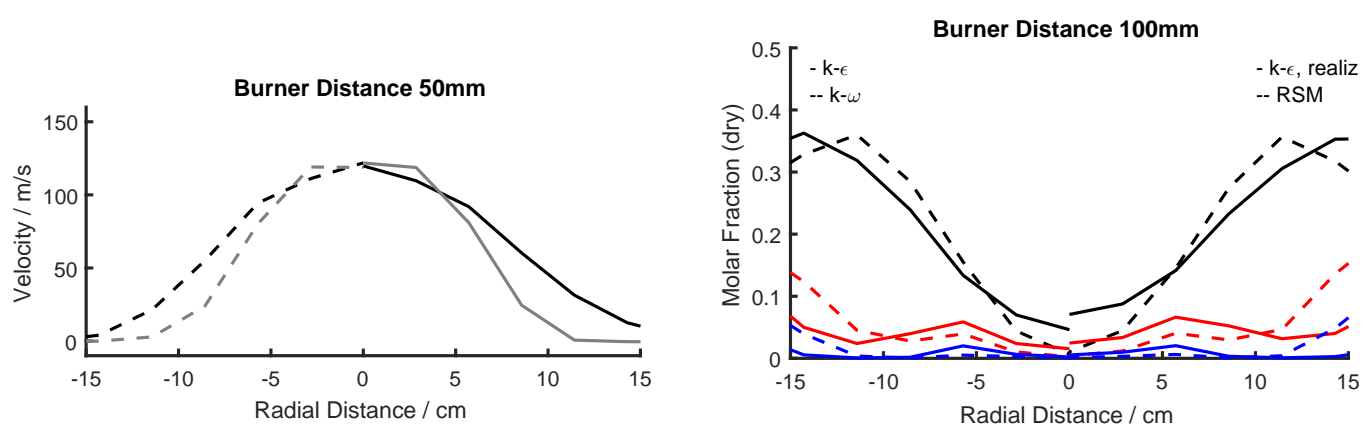

- $-\epsilon=-\mathbf{k}-\epsilon$, realiz $\square \mathrm{k}-\omega=-\mathrm{RSM}$


Figure 9: Axial velocities (Left) and composition (Right) predicted using the RSM and three other turbulence models. All the models use the HVI1 chemistry (see Table 1) 
twice smaller mean diameter $d_{\text {mean }}=50 \mu \mathrm{m}$. The spread parameter has been kept constant for both calculations. The direct effect of the aforementioned changes is the change of the droplets evaporation rate and as a consequence shifting of the evaporation region. Droplets are heated up mainly by convection and therefore for quick evaporation they have to leave the cold region present in the center of the reactor. As Figure 8 clearly shows (using the HVI1 model), the adopted diameter distribution in the main calculations $\left(d_{\text {mean }}=100 \mu \mathrm{m}, n=1.776\right)$ provides already the conditions for quick evaporation. Therefore, reducing the mean diameter by a factor of two, brings no major changes to the predictions.

On the contrary, by using a distribution with diameters increased by a factor of two, more liquid droplets tend to evaporate outside the hot thin flame region. The calculations do not show significant changes in the flow-field and only small changes in the flame are found. More observable differences appear in the composition of the recirculation zone and in the characteristics of the gasification region. Due to slower evaporation rates, the peaks present just outside the flame are flattened out. The tip of the flame has a slightly different form and $300 \mathrm{~K}$ higher temperatures since the endothermic evaporation process is not as intensive as in the standard calculations. The composition of the recirculation zone changes slightly, with the concentration of $\mathrm{CO}_{2}$ decreasing (in vol. dry) from the previously found value of $25 \%$ to $22.5 \%$ (\% vol. dry) and the CO increasing from $20 \%$ to $23 \%$ (\% vol. dry). Also the mole fraction of the hydrogen decreases from $18 \%$ to $16 \%$ (\% vol. dry).

Particularly important is the determination of the molecular diffusion of glycol-vapor as a function of temperature, needed for the determination of the evaporation rate (see Equation (24)). Since a change in the diffusivity 
leads to a quicker or a slower glycol evaporation, the consequences of using an inaccurate value are similar to the effects observed using smaller or bigger droplets.

\subsection{Gas radiation properties}

For the solution of the radiative transfer equation, Equation (27) in Section 2.4.1, radiative transfer coefficients have to be determined. As already stated, the RTE is valid for one single wavenumber only. In principle, the RTE must be solved for each wavenumber and then integrated over the whole wavenumber range to yield the total intensity $I=\int I_{\eta} \cdot \mathrm{d} \eta$. The gas absorption spectra of $\mathrm{H}_{2} \mathrm{O}, \mathrm{CO}_{2}$, and $\mathrm{CO}$ consists of several million individual spectral absorption lines. Different models exist which differ in CPU time requirement and accuracy. The most accurate is the line-by-line model which considers each individual absorption line using spectral databases like HITEMP-2010 [68] with a typical resolution of $\Delta \eta=0.01 \mathrm{~cm}^{-1}$.

In this work a gray-gases model (WSGGM) [69] has been developed based on accurate spectral line-by-line calculations using HITEMP-2010 database [68]. In this approach, the RTE is solved for each gray band $(k)$ separately, and weighted by its temperature weighting function $\left(w_{k}\right)$. Assuming negligible scattering, the RTE can then be written for each gray-gas [70]:

$$
\frac{\mathrm{d} I_{k}}{\mathrm{~d} s}=-a_{k} \cdot I_{k}+w_{k} \cdot a_{k} \cdot I_{\mathrm{b}}
$$

Summation over all contributions yields to the total intensity $I=\sum I_{k}$.

The same method, as described in [37-39], has been used to calculate absorption spectra as a starting point for the calculation of emissivity as a function of temperature for different pressure-path lengths $p_{a} \cdot L$ where $p$ is the sum of partial pressures of all radiatively participating molecules and $L$ is the optical path length. In the WSSGM the total emissivity is calculated 
using:

$$
\varepsilon^{\text {tot }}=\sum_{k=0}^{N_{g}} w_{k}(T) \cdot\left[1-\exp \left(-a_{k} \cdot p_{a} \cdot L\right)\right]
$$

where $N_{g}$ is the number of gray-gases, $w_{k}$ is the temperature scaling function of gas $k, a_{k}$ is the pressure-based absorption coefficient of pseudo gas $k$, and $p_{a} \cdot L$ is again the pressure path-length.

Taking into account three radiatively active gases, namely $\mathrm{H}_{2} \mathrm{O}$ [39], $\mathrm{CO}_{2}$ [37], and CO [71, 72], the pressure path-length $\left(p_{a} \cdot L\right)$ is given in the form:

$$
\left(p_{a} \cdot L\right)=P_{\mathrm{t}} \cdot\left(x_{\mathrm{H}_{2} \mathrm{O}}+x_{\mathrm{CO}_{2}}+x_{\mathrm{CO}}\right) \cdot L
$$

Using this definition we have produced an emissivity chart at atmospheric pressure, i. e. emissivity as a function of temperature for different pressure path-lengths, where the temperature has been varied between $450 \mathrm{~K}$ and $2950 \mathrm{~K}$ while the $\left(p_{a} \cdot L\right)$ values have been logarithmically varied between $0.001 \mathrm{bar} \mathrm{cm}$ to $6000 \mathrm{bar} \mathrm{cm}$ at 30 discrete values.

The mean values of the molar fractions corresponding to the REGA gasifier have been used for the calculation of each absorption spectrum.

While producing the emissivity chart, Figure 10, the carbon monoxide content in the line-by-line calculated absorption spectra is set to a constant value of $x_{\mathrm{CO}}=0.18$. The remaining parameter is then the mixing ratio of $\mathrm{MR}=x_{\mathrm{H}_{2} \mathrm{O}} / x_{\mathrm{CO}_{2}}$. Figure 10 shows the line-by-line calculated emissivity chart as well as the values calculated using the fitted WSGGM using 5 graygases (plus a clear-gas, $N_{g}=5$ ) and the 6 -th order weighting polynomials. The developed WSGGM differs by $0.017 \% \pm 1.272 \%$ from the line-by-line model. The same procedure has been used to fit this model to charts calculated at molar ratios $\mathrm{MR}=1.5 \ldots 3.3$ by altering the amount of $\mathrm{CO}_{2}$. Altogether 13 WSGGM have been produced, each model with an accuracy of $\pm 6 \%$. The produced sets of tabulated values have been implemented into 


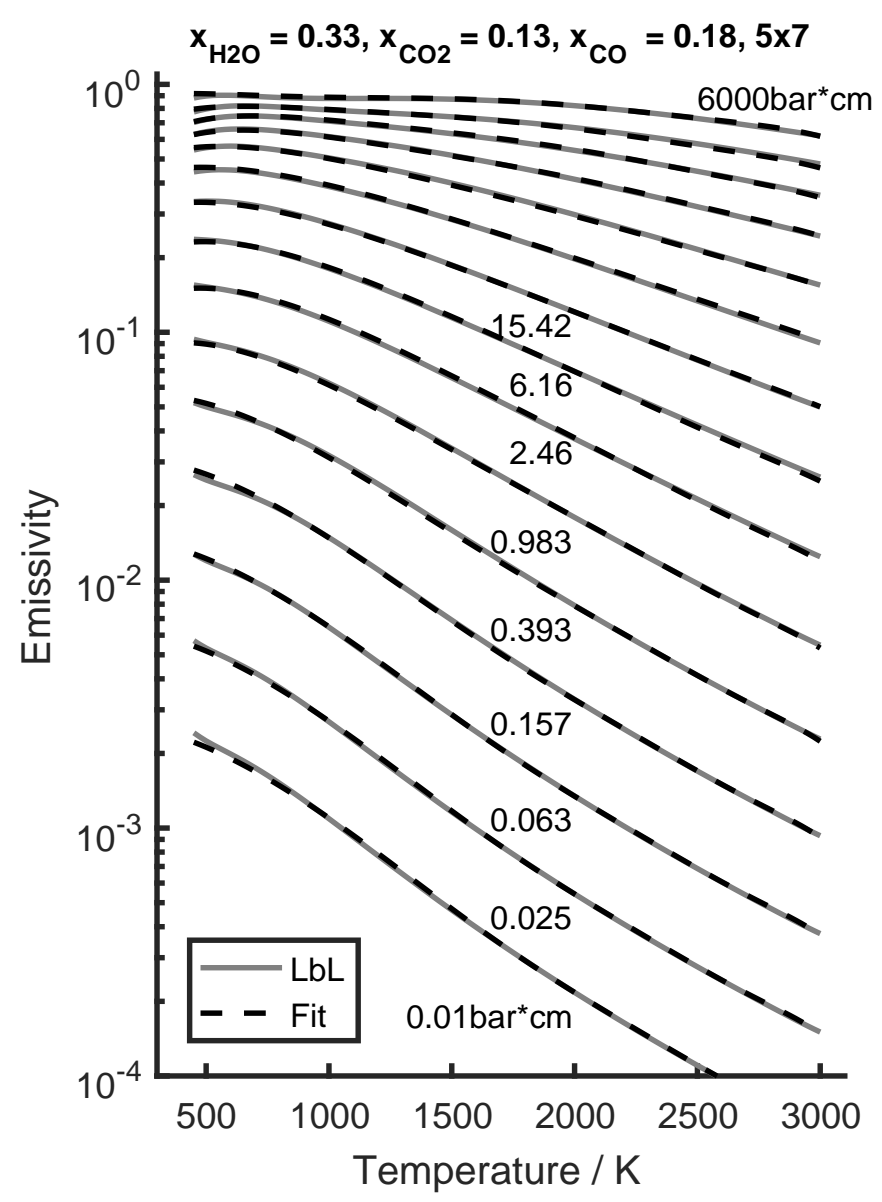

Figure 10: Example of a fitted WSGGM using 5 gray-gases (plus a clear-gas) and a $6^{\text {th }}$ order polynomial for the weighting function. Emissivities calculated using the fitted WSGGM differ by $0.017 \% \pm 1.272 \%$ from the line-by-line calculated values. 
the radiation solver and in each computational cell radiative properties are evaluated using the local composition (mixing ratio).

The CFD calculations have been carried out using either a constant emissivity, determined using a typical gas composition inside the gasifier and a typical temperature, or the developed WSGGM is used which facilitate a variable absorption. The constant absorption coefficient $(a)$ for the DO solver is then calculated through the mean beam length $\left(L_{\mathrm{eq}}\right)$ :

$$
a=-\frac{\ln (1-\varepsilon)}{L_{\mathrm{eq}}}=0.53 \mathrm{~m}^{-1}
$$

In what follows, the calculation using the constant absorption coefficient is used as a reference case. Figure 11 shows the change in absorption coefficient for the reference calculation and the usage of the WSGGM. The absorption coefficient in case of the WSGGM is an average value calculated through:

$$
\bar{a}=p_{a} \cdot \sum_{k=0}^{5} w_{k}(T) \cdot a_{k}
$$

It can be seen that the absorption coefficient is larger than the constant value $\left(0.53 \mathrm{~m}^{-1}\right)$ almost throughout the whole domain. Since the absorption coefficient is related to the temperature, as shown in Figure 11, the value calculated using the WSGGM is smaller at elevated temperatures while it is larger at low temperatures, if compared to the assumed constant value of $0.53 \mathrm{~m}^{-1}$. The radiation flux incident on the walls changes only slightly and most of the changes are in the near-flame region. The radiation source changes especially in the flame region but, the effect on the temperature field is small since in this region the energy source due to the chemical reactions is much larger (around two orders of magnitude) if compared to the radiative contribution. Furthermore, in the flame-core region there are plenty of MEG droplets that contribute to the radiation. 

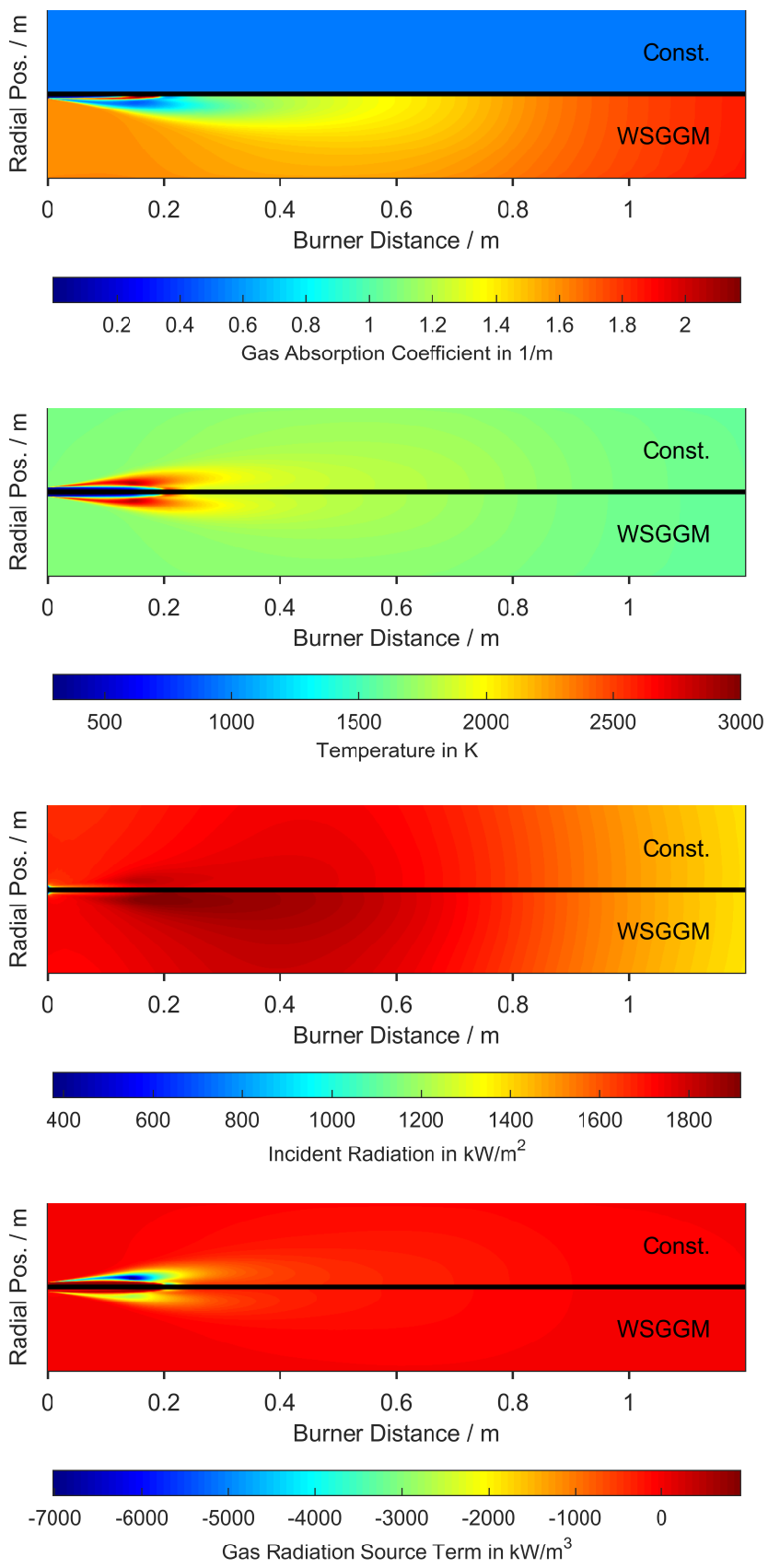

Figure 11: Effect of the WSGGM on (i) the absorption coefficient,(ii) the temperature field,(iii) the wall incident radiation, and (iv) the gas radiation source term. 
Figure 12 shows the wall incident radiation, the radiative as well as total (radiative plus convective) heat flux to the inner wall of the REGA reactor, and the inner wall temperature. Due to the WSGGM the surface incident radiation is increased in the near-flame region so that the wall temperature is also slightly increased. As can be seen in Figure 12, the radiative heat flux to the wall significantly increases whereas the total heat flux increases to a lesser extent since due to the higher wall temperature the convective heat transfer decreases. The total heat flux to the wall (radiation + convection) is $34.22 \mathrm{~kW}$ (reference case) and $36.17 \mathrm{~kW}$ (WSGGM), whereas for the radiative heat flux alone values of $26.41 \mathrm{~kW}$ (reference case) and $33.59 \mathrm{~kW}$ (WSGGM) are applicable so that in case of the WSGGM the contribution of radiation is more pronounced if compared to the convective part.

\subsection{Absorption and Scattering on droplets}

Besides the gas radiation, also the contribution of the droplets must be taken into account. In contrast to gaseous molecules, droplets do not only emit and absorb but also scatter radiation. Assuming spherical droplets, scattering coefficients can be calculated using the Mie-Lorentz theory [59, 73]; the absorption coefficient depends on the droplet diameter or more precisely on the diameter distribution (see section 3.1). Calculations of the volume fraction using the determined diameter distribution for REGA-glycol-T1 conditions have shown that the scattering can be treated as independent [59] and the scattering inside the small cell volume take place on single droplet.

The absorption and the scattering coefficients on a single particle generally depend on the size parameter $x=\pi \cdot D \cdot \eta$ and the complex index of refraction $m$ which, for glycol, is taken from Sani and Dell' Oro [74]. For details on the calculation, the reader is referred to [59, 73].

The absorption as well as scattering coefficients are calculated during the 

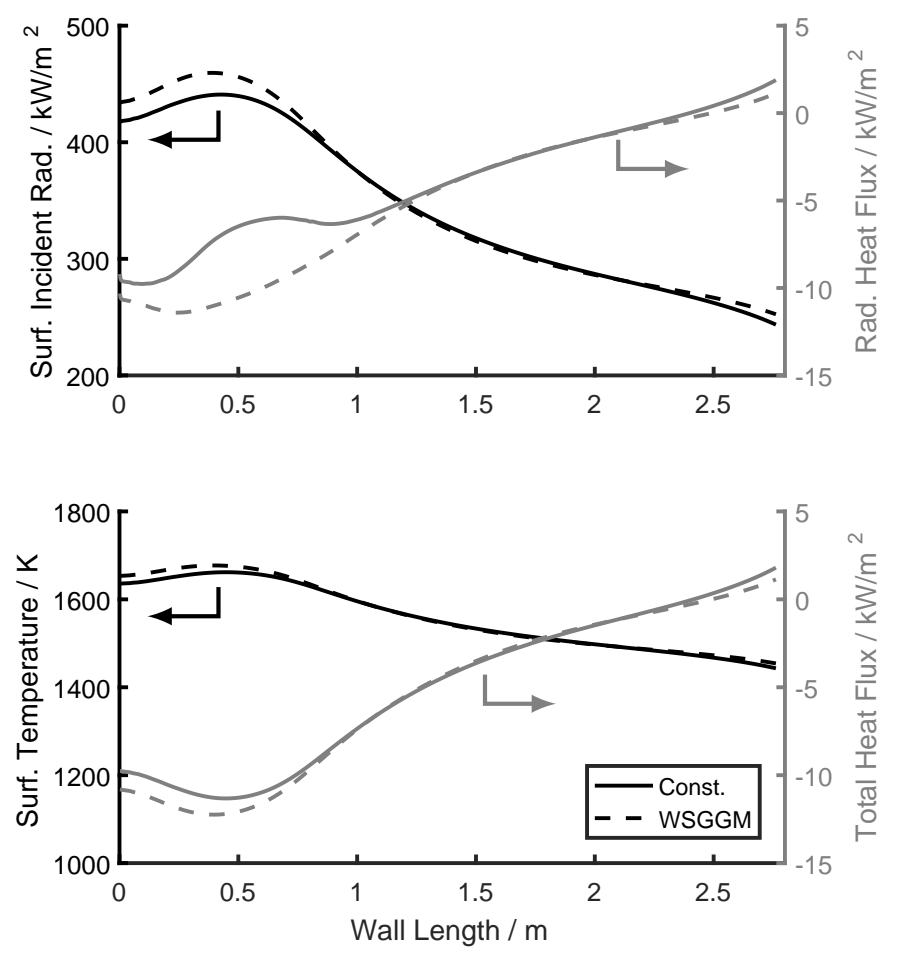

Figure 12: Effect of the WSGGM on (i) the wall surface incident radiation, (ii) the radiative as well as (iii) the total (radiation + conduction) heat flux to the wall, and (vi) the wall temperature. 
droplets tracking and are evaluated as mean values for all droplets; the phase function is taken as a fluid property so that one function is used only.

It should be emphasized that the calculations are based on the inlet droplet size distribution. Due to the droplet evaporation, the real distribution is tilted towards smaller diameter resulting in a more isotropic phasefunction.

In the reference calculation, we have used a constant particle absorption coefficient of $Q_{a b s}=0.5$ and isotropic scattering, i. e. a constant phase function of $\Phi=1$, whereas in the modified case, we have included the particle absorption coefficient as a function of droplet diameter for a source temperature of $1400 \mathrm{~K}$.

In Figure 13 the differences between the two approaches are shown. It can be seen that, since the droplets are almost completely evaporated at a distance of $50 \mathrm{~cm}$, the contribution of the droplet radiation to the radiative heat transfer is negligible. Neither the particle radiation source term nor the incident radiation nor the gas temperature change due to the extended model. The particle radiation source term exhibits a large maximum value if compared to the gas radiation source term but this observation is valid at the droplet injection point only. Due to the different absorption coefficients, the evaporation rate of the droplets might be influenced resulting in a slightly different gas composition. However, at $300 \mathrm{~mm}$ distance, such differences in radiation invoke $0.05 \%$ changes in gas composition. 

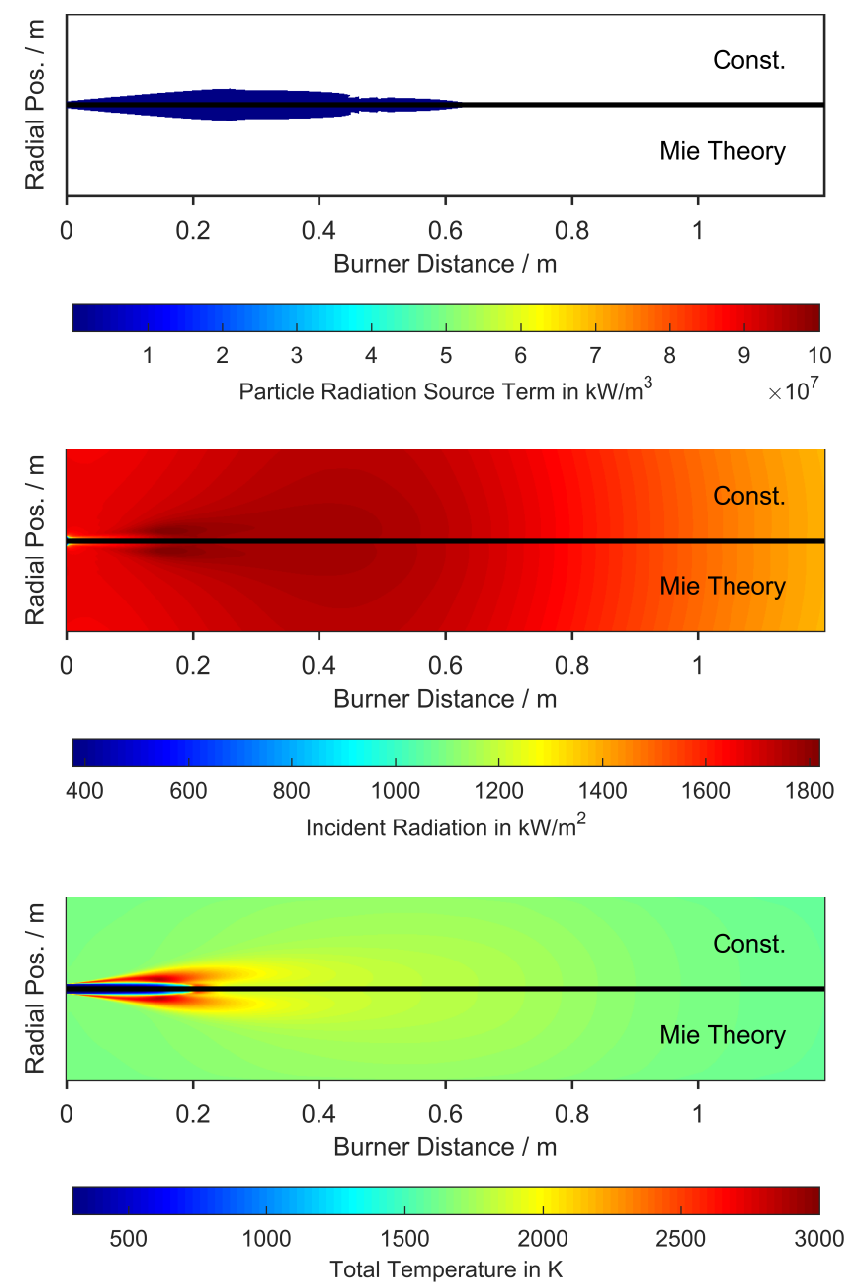

Figure 13: Influence of the Mie-theory-based particle radiation model on (Top) the particle radiation source term, (in plotting limited to a minimum value of $10 \mathrm{~kW} / \mathrm{m}^{2}$ ), (Center) the wall incident radiation, and (Button) the gas temperature. (Const.) simulations performed using a constant $\left(a=0.53 \mathrm{~m}^{-1}\right)$ absorption coefficient; (Mie-Theory) simulations performed using absorption and scattering coefficients calculated using Mie Theory (see Text) 


\section{Conclusions}

We have carried out CFD simulations of REGA-glycol-T1 experimental campaign [40] concerning gasification of glycol in an oxygen-nitrogen mixture at an absolute stoichiometry of 0.74. In the steady-state RANS-based simulations, the reacting flow-field has been computed using a number of turbulence models while turbulence-chemistry interactions have been modeled using either the Eddy Dissipation Concept (EDC) or the presumed PDF approach. In conjunction with the EDC, two global-chemistry schemes have been used: the HVI1-scheme for glycol gasification and the extended JonesLindstedt scheme. The presumed PDF model has been combined with a chemical equilibrium procedure. Radiation has been computed using the Discrete Ordinate Method with a comprehensive analysis concerning absorption/emission of infrared radiation by gaseous molecules as well as absorption and scattering on droplets. The following has been concluded:

(a) The in-gasifier flow-pattern consisting of the glycol spray and the gasification medium (oxygen-air mixture) jet, both driving a strong recirculation zone bringing the syngas back to the near atomizer region, has been well predicted using the RANS models. Only little sensitivity of the flowfield predictions to turbulence model variations and the chemical schemes has been observed.

(b) The CFD-predictions of the near-atomizer region are sensitive and strongly dependent on the sub-models used; the spray sub-model being perhaps the most important. The effect of the chemical scheme used for the near-atomizer predictions has also been substantial.

(c) The simulations have identified the existence of several distinct reaction zones. Near the glycol atomizer, there exists a central spray zone where droplets are being produced and evaporation takes place. The zone extends 
up to $150 \mathrm{~mm}$ distance (around 25 equivalent nozzle diameters) downstream of the atomizer and is enveloped by a high temperature flame which is located at the boundary between the forward flow of the central jet and the strong recirculation zone. The recirculation zone extends down to $800 \mathrm{~mm}$ distance (around 130 equivalent nozzle diameters) transporting hot syngas back to the burner. The syngas, entrained into the gasification medium stream, reacts with oxygen at locally oxygen-rich (combustion) conditions.

(d) Good quality predictions of temperature and chemical species (CO, $\mathrm{H}_{2}, \mathrm{CO}_{2}, \mathrm{H}_{2} \mathrm{O}, \mathrm{CH}_{4}$ ) concentrations at $300 \mathrm{~mm}$ and $680 \mathrm{~mm}$ distances from the atomizer have been obtained. The HVI1 global chemistry scheme has predicted very well not only the $\mathrm{CO} / \mathrm{CO}_{2}$ ratios but also the trace concentrations of methane. The eJL scheme happens to be less accurate.

(e) The radiative transfer calculations accounting for the presence of droplets have been very elaborate. We have demonstrated that such calculations can be drastically simplified using a constant value of the absorption coefficient provided that the value is determined using proper spectral line-by-line calculations. With such determined absorption coefficient the radiative fluxes, and the radiative source in the enthalpy (energy) equation, are accurately calculated.

\section{Acknowledgements}

Part of this work was funded by the Helmholtz Association of German Research Centres (HGF) in the frame of the Helmholtz Virtual Institute for Gasification Technology - HVIGasTech (VH-VI-429) [30, 31]. The authors gratefully acknowledge the financial support. 


\section{References}

\section{References}

[1] C. Y. Wen, T. Z. Chaung, Entrainment Coal Gasification Modeling, Industrial \& Engineering Chemistry Process Design and Development 18 (4) (1979) 684-695, ISSN 0196-4305, URL http://dx.doi.org/10. 1021/i260072a020.

[2] R. Govind, J. Shah, Modeling and simulation of an entrained flow coal gasifier, AIChE Journal 30 (1) (1984) 79-92, ISSN 1547-5905, URL http://dx.doi.org/10.1002/aic.690300113.

[3] L. Smoot, B. Brown, Controlling mechanisms in gasification of pulverized coal, Fuel 66 (9) (1987) 1249-1256, ISSN 0016-2361, URL http://dx.doi.org/10.1016/0016-2361(87)90063-9.

[4] B. W. Brown, L. D. Smoot, P. J. Smith, P. O. Hedman, Measurement and prediction of entrained-flow gasification processes, AIChE Journal 34 (3) (1988) 435-446, ISSN 1547-5905, URL http://dx.doi.org/10. 1002/aic.690340311.

[5] M. Seggiani, Modelling and simulation of time varying slag flow in a Prenflo entrained-flow gasifier, Fuel 77 (14) (1998) 1611-1621, ISSN 0016-2361, URL http://dx.doi.org/10.1016/S0016-2361(98) 00075-1.

[6] D. F. Fletcher, B. S. Haynes, J. Chen, S. D. Joseph, Computational fluid dynamics modelling of an entrained flow biomass gasifier, Applied Mathematical Modelling 22 (10) (1998) 747-757, ISSN 0307-904x, URL http://dx.doi.org/10.1016/S0307-904X (98)10025-2. 
[7] D. F. Fletcher, B. S. Haynes, F. C. Christo, S. D. Joseph, A CFD based combustion model of an entrained flow biomass gasifier, Applied Mathematical Modelling 24 (3) (2000) 165-182, ISSN 0307-904x, URL http://dx.doi.org/10.1016/S0307-904X (99)00025-6.

[8] C. Chen, T. Miyoshi, H. Kamiya, M. Horio, T. Kojima, On the scalingup of a two-stage air blown entrained flow coal gasifier, The Canadian Journal of Chemical Engineering 77 (4) (1999) 745-750, ISSN 1939019X, URL http://dx.doi.org/10.1002/cjce.5450770416.

[9] C. Chen, M. Horio, T. Kojima, Numerical simulation of entrained flow coal gasifiers. Part I: Modeling of coal gasification in an entrained flow gasifier, Chemical Engineering Science 55 (18) (2000) 3861-3874, ISSN 0009-2509, URL http://dx.doi.org/10.1016/S0009-2509(00) 00030-0.

[10] C. Chen, M. Horio, T. Kojima, Numerical simulation of entrained flow coal gasifiers. Part II: Effects of operating conditions on gasifier performance, Chemical Engineering Science 55 (18) (2000) 3875-3883, ISSN 0009-2509, URL http://dx.doi.org/10.1016/S0009-2509(00) 00031-2.

[11] C. Chen, M. Horio, T. Kojima, Use of numerical modeling in the design and scale-up of entrained flow coal gasifiers, Fuel 80 (10) (2001) 1513-1523, ISSN 0016-2361, URL http://dx.doi.org/10. 1016/S0016-2361(01) 00013-8.

[12] C. K. Westbrook, F. L. Dryer, Simplified reaction mechanisms for the oxidation of hydrocarbon fuels in flames, Combustion Science and Tech- 
nology 27 (1-2) (1981) 31-43, ISSN 0010-2202, URL http://dx.doi. org/10.1080/00102208108946970.

[13] W. P. Jones, R. P. Lindstedt, Global reaction schemes for hydrocarbon combustion, Combustion and Flame 73 (3) (1988) 233-249, ISSN 00102180, URL http://dx.doi.org/10.1016/0010-2180(88)90021-1.

[14] H. Liu, C. Chen, T. Kojima, Theoretical simulation of entrained flow IGCC gasifiers. Effect of mixture fraction fluctuation on reaction owing to turbulent flow, Energy \& Fuels 16 (5) (2002) 1280-1286, ISSN 08870624, URL http://dx.doi.org/10.1021/ef 0200626.

[15] H. Liu, T. Kojima, C. Chen, Interaction between a turbulent flow and reaction under various conditions in oxygen blown HYCOL gasifiers, Developments in Chemical Engineering and Mineral Processing 11 (5-6) (2003) 557-577, ISSN 0969-1855, URL http://dx.doi.org/10.1002/ apj. 5500110613 .

[16] H. Liu, T. Kojima, Theoretical study of coal gasification in a 50 ton/day HYCOL entrained flow gasifier. I. Effects of coal properties and implications, Energy \& Fuels 18 (4) (2004) 908-912, ISSN 0887-0624, URL http://dx.doi.org/10.1021/ef030162r.

[17] H. Liu, T. Kojima, Theoretical study of coal gasification in a 50 ton/day HYCOL entrained flow gasifier. II. Effects of operating conditions and comparison with pilot-scale experiments, Energy \& Fuels 18 (4) (2004) 913-917, ISSN 0887-0624, URL http://dx.doi.org/10. 1021/ef030163j.

[18] W. Vicente, S. Ochoa, J. Aguillón, E. Barrios, An Eulerian model for the simulation of an entrained flow coal gasifier, Applied Thermal 
Engineering 23 (15) (2003) 1993-2008, ISSN 1359-4311, URL http: //dx.doi.org/10.1016/S1359-4311(03)00149-2.

[19] M. Marklund, Pressurized entrained-flow high temperature black liquor gasification: CFD based reactor scale-up method and spray burner characterization, Doctoral thesis, Luleå tekniska universitet, Luleå, URL http://pure.ltu.se/portal/files/162271/LTU-DT-0642-SE. pdf, 2006.

[20] M. Marklund, R. Tegman, R. Gebart, CFD modelling of black liquor gasification: Identification of important model parameters, Fuel 86 (1213) (2007) 1918-1926, ISSN 0016-2361, URL http://dx.doi.org/10. 1016/j.fuel.2006.12.015.

[21] P. Carlsson, M. Marklund, E. Furusjö, H. Wiinikka, R. Gebart, Black liquor gasification: CFD model predictions compared with measurements, in: Technical Association of the Pulp and Paper Industry (Ed.), 2010 International Chemical Recovery Conference proceedings, vol. 2, TAPPI Press, Norcross (GA), ISBN 978-1-595-101983, 160-171, URL http://imisrise.tappi.org/TAPPI/Products/10/ ICR/10ICRC53. aspx, 2010.

[22] A. Silaen, T. Wang, Effect of turbulence and devolatilization models on coal gasification simulation in an entrained-flow gasifier, International Journal of Heat and Mass Transfer 53 (9-10) (2010) 2074-2091, ISSN 0017-9310, URL http://dx.doi.org/10.1016/j . ijheatmasstransfer.2009.12.047.

[23] M. Kumar, A. F. Ghoniem, Multiphysics simulations of entrained flow gasification. Part I: Validating the nonreacting flow solver and the par- 
ticle turbulent dispersion model, Energy \& Fuels 26 (1) (2012) 451-463, ISSN 0887-0624, URL http://dx.doi.org/10.1021/ef200884j.

[24] M. Kumar, A. F. Ghoniem, Multiphysics simulations of entrained flow gasification. Part II: Constructing and validating the overall model, Energy \& Fuels 26 (1) (2012) 464-479, ISSN 0887-0624, URL http: //dx.doi.org/10.1021/ef2008858.

[25] N. Abani, A. F. Ghoniem, Large eddy simulations of coal gasification in an entrained flow gasifier, Fuel 104 (2013) 664-680, ISSN 0016-2361, URL http://dx.doi.org/10.1016/j.fuel.2012.06.006.

[26] X. Lu, T. Wang, Investigation of radiation models in entrained-flow coal gasification simulation, International Journal of Heat and Mass Transfer 67 (2013) 377-392, ISSN 0017-9310, URL http://dx.doi.org/10. 1016/j.ijheatmasstransfer.2013.08.011.

[27] X. Ku, T. Li, T. Løvås, Eulerian-Lagrangian simulation of biomass gasification behavior in a high-temperature entrained-flow reactor, Energy \& Fuels 28 (8) (2014) 5184-5196, ISSN 0887-0624, URL http: //dx.doi.org/10.1021/ef5010557.

[28] X. Gao, Y. Zhang, B. Li, X. Yu, Model development for biomass gasification in an entrained flow gasifier using intrinsic reaction rate submodel, Energy Conversion and Management 108 (2016) 120-131, ISSN 01968904, URL http://dx.doi.org/10.1016/j.enconman.2015.10.070.

[29] Karlsruhe Institute of Technology, Helmholtz Virtual Institute for Gasification Technology (HVIGasTech), URL http://www.hvigastech. org/, 2016. 
[30] T. Jakobs, N. Djordjevic, S. Fleck, M. Mancini, R. Weber, T. Kolb, Gasification of high viscous slurry $R \& D$ on atomization and numerical simulation, Applied Energy 93 (2012) 449 - 456, ISSN 03062619, doi: \bibinfo \{doi\}\{http://dx.doi.org/10.1016/j.apenergy.2011.12. 026\}, URL http://www.sciencedirect.com/science/article/pii/ S0306261911008221, (1) Green Energy; (2)Special Section from papers presented at the 2nd International Enery 2030 Conf.

[31] T. Kolb, M. Aigner, R. Kneer, M. Müller, R. Weber, N. Djordjevic, Tackling the challenges in modelling entrained-flow gasification of lowgrade feedstock, Journal of the Energy Institute 89 (2016) 485-503, ISSN 1743-9671, doi: \bibinfo \{doi\}\{http://dx.doi.org/10.1016/j.joei.2015.07. 007\}, URL http://www.sciencedirect.com/science/article/pii/ S1743967115300027.

[32] S. Hafner, A. Rashidi, G. Baldea, U. Riedel, A detailed chemical kinetic model of high-temperature ethylene glycol gasification, Combustion Theory and Modelling 15 (4) (2011) 517-535, ISSN 1364-7830, URL http://dx.doi.org/10.1080/13647830.2010.547602.

[33] A. Rashidi, CFD simulation of biomass gasification using detailed chemistry, Dissertation, Ruprecht-Karls-Universität Heidelberg, Heidelberg, URL http://www.ub.uni-heidelberg.de/archiv/11654, 2011.

[34] M. Mancini, R. Buczynski, R. Weber, S. Fleck, P. Stoesser, T. Kolb, Gasification of Glycol: Measurements and Mathematical Modelling, in: VDI Verlag (Ed.), 25. Deutscher Flammentag - Verbrennung und Feuerung: VDI Berichte 2119, ISBN 978-3-180-92119-8, 221-226, 2011.

[35] M. Mancini, R. Weber, P. Weigand, W. Leuckel, T. Kolb, Design of the 
entrained flow reactor for gasification of biomass based slurry, in: VDI Verlag (Ed.), 26. Deutscher Flammentag - Verbrennung und Feuerung: VDI Berichte 2161, ISBN 978-3-180-92161-7, 625-634, 2013.

[36] M. Alberti, R. Weber, M. Mancini, M. F. Modest, Comparison of models for predicting band emissivity of carbon dioxide and water vapour at high temperatures, International Journal of Heat and Mass Transfer 64 (2013) 910-925, ISSN 0017-9310, URL http://dx.doi.org/10.1016/ j.ijheatmasstransfer.2013.05.011.

[37] M. Alberti, R. Weber, M. Mancini, Re-creating Hottel's emissivity charts for carbon dioxide and extending them to 40 bar pressure using HITEMP-2010 data base, Combustion and Flame 162 (3) (2015) 597-612, ISSN 0010-2180, URL http://dx.doi.org/10.1016/ j.combustflame.2014.09.005.

[38] M. Alberti, R. Weber, M. Mancini, A. Fateev, S. Clausen, Validation of HITEMP-2010 for carbon dioxide and water vapour at high temperatures and atmospheric pressures in $450-7600 \mathrm{~cm}-1$ spectral range, Journal of Quantitative Spectroscopy and Radiative Transfer 157 (2015) 14-33, ISSN 0022-4073, URL http://dx.doi.org/10.1016/j.jqsrt. 2015.01 .016 .

[39] M. Alberti, R. Weber, M. Mancini, Re-creating Hottel's emissivity charts for water vapor and extending them to 40 bar pressure using HITEMP2010 data base, Combustion and Flame 169 (2016) 141-153, ISSN 00102180, URL http://dx.doi.org/10.1016/j.combustflame.2016.04. 013.

[40] S. Fleck, U. Santo, C. Hotz, T. Jakobs, G. Eckel, M. Mancini, R. We- 
ber, T. Kolb, Entrained Flow Gasification. Part 1: Gasification of glycol in an atmospheric-pressure experimental rig, Fuel 217 (2018) 306-319, ISSN 0016-2361, doi:〈bibinfo \{doi\}\{https://doi.org/10.1016/ j.fuel.2017.12.077\}, URL http://www.sciencedirect.com/science/ article/pii/S0016236117316551.

[41] G. Eckel, P. L. Clercq, T. Kathrotia, A. Saenger, S. Fleck, M. Mancini, T. Kolb, M. Aigner, Entrained flow gasification. Part 3: Insight into the injector near-field by Large Eddy Simulation with detailed chemistry, Fuel 223 (2018) 164 - 178, ISSN 0016-2361, doi:\bibinfo \{doi\}\{https://doi.org/10.1016/j.fuel.2018.02. 176\}, URL http://www.sciencedirect.com/science/article/pii/ S0016236118303727.

[42] B. E. Launder, G. J. Reece, W. Rodi, Journal of Fluid Mechanics, Progress in the Development of a Reynolds-Stress Turbulent Closure 63 (1975) 537-566.

[43] R. Weber, F. Boysan, J. Swithenbank, P. A. Roberts, Computations of Near Field Aerodynamics of Swirling Expanding Flows, The $21^{\text {st }}$ Symposium (International) on Combustion. The Combustion Institute (1986) $1435-1443$.

[44] B. Launder, D. Spalding, The Numerical Computation of Turbulent Flows, Computer Methods in Applied Mechanics and Engineering 3 (1974) 269-289.

[45] T. Shih, W. W. Liou, A. Shabbir, J. Zhu, A New k- $\epsilon$ Eddy-Viscosity Model for High Reynolds Number Turbulent Flows: Model Development and Validation, Computers Fluids 24(3) (1995) 227-238. 
[46] B. E. Launder, D. B. Spalding, Lectures in Mathematical Models of Turbulence, Academic Press, London, England, 1972.

[47] D. Wilcox, Re-assessment of the scale-determining equation for advanced turbulence models, AIAA Journal 26 (11) (1988) 1299-1310.

[48] F. R. Menter, Two-Equation Eddy-Viscosity Turbulence Models for Engineering Applications, AIAA Journal 32 (8) (1994) 1598-1605.

[49] S. A. Morsi, A. J. Alexander, An Investigation of Particle Trajectories in Two-Phase Flow Systems, Fluid Mechanics 55 (2) (1972) 193-208.

[50] F. Boysan, W. H. Ayer, J. Swithenbank, A Fundamental mathematical modeling approach to cyclone design, Transactions of the Institution of Chemical Engineering 60 (1982) 222-230.

[51] R. Weber, F. Boysan, J. Swithenbank, Simulation of Dispersion of Heavy Particles in Confined Turbulent Flows., AIChE Journal 30 (3) (1984) S. 490-492.

[52] F. Boysan, R. Weber, J. Swithenbank, C. J. Lawn, Modeling Coal-Fired Cyclone Combustors, Combustion and Flame 63 (1986) S. 73-86.

[53] NIST-JANAF Thermochemical Tables, American Chemical Society and the American Institute of Physics for the National Institute of Standards and Technology, 1998.

[54] W. Ranz, W. Marshall, Evaporation from drops: part II, Chem Eng Prog 48 (1952) 173-180.

[55] D. Spalding, The Combustion of Liquid Fuels., Proceedings of the Combustion Institute 4 (1) (1953) 847-864. 
[56] W. Fiveland, A. Jamaluddin, Three-dimensional spectral radiative heat transfer solutions by the discrete-ordinates method, Journal of Thermophysics and Heat Transfer 5 (3) (1991) 335-339, doi: $\backslash$ bibinfo $\{$ doi $\}\{10$. $2514 / 3.268\}$.

[57] E. Chui, G. Raithby, Computation of Radiant Heat Transfer on a Nonorthogonal Mesh using the Finite-Volume Method, Numerical Heat Transfer, Part B: Fundamentals 23 (3) (1993) 269-288, doi: $\backslash$ bibinfo $\{$ doi $\}\{10.1080 / 10407799308914901\}$.

[58] J. Murthy, S. Mathur, Finite Volume Method for Radiative Heat Transfer Using Unstructured Meshes, Journal of Thermophysics and Heat Transfer 12 (3) (1998) 313-321.

[59] M. Modest, Radiative Heat Transfer, Academic Press, 3 edn., 2013.

[60] J. Howell, M. Mengüę, R. Siegel, Thermal Radiation Heat Transfer, Taylor \& Francis Group, 6 edn., 2016.

[61] I. S. Ertesvag, B. F. Magnussen, The Eddy Dissipation Turbulence Energy Cascade Model, Combust. Sci. and Tech. 159 (2000) 213-135.

[62] S. Pope, PDF methods for turbulent reactive flows, Progress in Energy and Combustion Science 11 (2) (1985) 119 - 192, ISSN 0360-1285, doi: \bibinfo \{doi\}\{10.1016/0360-1285(85)90002-4\}, URL http://www . sciencedirect.com/science/article/pii/0360128585900024.

[63] B. Magnussen, B. Hjertager, On mathematical models of turbulent combustion with special emphasis on soot formation and combustion, in: In 16th Symp. on Combustion., vol. 16, The Combustion Institute, 719$729,1976$. 
[64] G. P. Smith, D. M. Golden, M. Frenklach, N. W. Moriarty, B. Eiteneer, M. Goldenberg, C. T. Bowman, R. K. Hanson, S. Song, J. William C. Gardiner, V. V. Lissianski, Z. Qin, GRI mechanism 3.0, Tech. Rep., Sandia National Laboratories, http://www.me.berkeley.edu/gri_mech/, 2000 .

[65] H. Watanabe, M. Otaka, Numerical simulation of coal gasification in entrained flow coal gasifier, Fuel 85 (12-13) (2006) 1935-1943, ISSN 0016-2361, URL http://dx.doi.org/10.1016/j.fuel.2006.02.002.

[66] S. Halama, H. Spliethoff, Numerical simulation of entrained flow gasification: Reaction kinetics and char structure evolution, Fuel Processing Technology 138 (2015) 314-324, ISSN 0378-3820, URL http: //dx.doi.org/10.1016/j.fuproc.2015.05.012.

[67] B. Kader, Temperature and Concentration Profiles in Fully Turbulent Boundary Layers, Int. J. Heat Mass Transfer 24 (9) (1981) 1541-1544.

[68] L. Rothman, I. Gordon, R. Barber, H. Dothe, R. Gamache, A. Goldman, V. Perevalov, S. Tashkun, J. Tennyson, HITEMP, the high-temperature molecular spectroscopic database, Journal of Quantitative Spectroscopy \& Radiative Transfer 111 (15) (2010) 2139 - 2150, doi: $\backslash$ bibinfo $\{$ doi $\}\{10$. 1016/j.jqsrt.2010.05.001\}.

[69] H. Hottel, A. Sarofim, Radiative Transfer, MacGraw-Hill, 1967.

[70] M. Modest, The Weighted-Sum-of-Gray-Gases Model for Arbitrary Solution Methods in Radiative Transfer, Journal of Heat Transfer 113 (3) (1991) 650-656, doi: \bibinfo \{doi $\}\{10.1115 / 1.2910614\}$.

[71] M. Alberti, R. Weber, M. Mancini, Absorption of infrared radiation by 
Carbon Monoxide at elevated temperatures and pressures. Part A. Development of a line-by-line procedure based on HITEMP-2010, Journal of Quantitative Spectroscopy \& Radiative Transfer submitted in 2016.

[72] M. Alberti, R. Weber, M. Mancini, Absorption of infared radiation by Carbon Monoxide at elevated temperatures and pressures. Part B. Total emissivity charts and correlations, Journal of Quantitative Spectroscopy \& Radiative Transfer submitted in 2016.

[73] H. van de Hulst, Light Scattering by Small Particles, Dover Publications, Inc., reprint of the John Wiley \& Sons, Inc., New York, 1957 edition, 1981.

[74] E. Sani, A. Dell'Oro, Optical constants of ethylene glycol over an extremely wide spectral range, Optical Materials 37 (2014) 36-41, doi: $\backslash$ bibinfo $\{$ doi $\}\{10.1016 /$ j.optmat.2014.04.035\}. 